University of Wollongong

Research Online

Faculty of Engineering and Information

Faculty of Engineering and Information

Sciences - Papers: Part A

Sciences

$1-1-2015$

\title{
Unified cyclic stress-strain model for normal and high strength concrete confined with FRP
}

$\mathrm{T} \mathrm{Yu}$

University of Wollongong, taoy@uow.edu.au

B Zhang

The Hong Kong Polytechnic University

J G. Teng

The Hong Kong Polytechnic University, cejgteng@polyu.edu.hk

Follow this and additional works at: https://ro.uow.edu.au/eispapers

Part of the Engineering Commons, and the Science and Technology Studies Commons

Research Online is the open access institutional repository for the University of Wollongong. For further information contact the UOW Library: research-pubs@uow.edu.au 


\title{
Unified cyclic stress-strain model for normal and high strength concrete confined with FRP
}

\author{
Abstract \\ Fiber reinforced polymer (FRP) has become increasingly popular as a confining material for concrete, \\ both in the strengthening of existing columns where FRP wraps with fibers oriented completely or \\ predominantly in the hoop direction are typically used, and in new construction where filament-wound \\ FRP tubes with fibers oriented at desired angles to the longitudinal axis are typically used. For both types \\ of applications, the stress-strain behavior of FRP-confined concrete under cyclic axial compression needs \\ to be properly understood and modeled for the accurate simulation of such columns under seismic \\ loading. This paper presents an improved cyclic stress-strain model for FRP-confined concrete on the \\ basis of a critical assessment of an earlier model proposed by Lam and Teng in 2009 by making use of a \\ database containing new test results of both concrete-filled FRP tubes (CFFTs) and concrete cylinders \\ confined with an FRP wrap. The assessment reveals several deficiencies of Lam and Teng's model due to \\ the limited test results available to them. The proposed model corrects these deficiencies and is shown to \\ provide reasonably accurate predictions for both concrete in CFFTs and concrete confined with an FRP \\ wrap and for both normal strength concrete (NSC) and high strength concrete (HSC).

\section{Disciplines} \\ Engineering | Science and Technology Studies

\section{Publication Details} \\ Yu, T., Zhang, B. \& Teng, J. G. (2015). Unified cyclic stress-strain model for normal and high strength \\ concrete confined with FRP. Engineering Structures, 102 189-201.
}




\title{
UNIFIED CYCLIC STRESS-STRAIN MODEL FOR NORMAL AND
} HIGH STRENGTH CONCRETE CONFINED WITH FRP

\author{
T. Yu ${ }^{1 *}$, B. Zhang ${ }^{2}$ and J.G. Teng ${ }^{3}$
}

\section{ABSTRACT}

Fiber reinforced polymer (FRP) has become increasingly popular as a confining material for concrete, both in the strengthening of existing columns where FRP wraps with fibers oriented completely or predominantly in the hoop direction are typically used, and in new construction where filament-wound FRP tubes with fibers oriented at desired angles to the longitudinal axis are typically used. For both types of applications, the stress-strain behavior of FRP-confined concrete under cyclic axial compression needs to be properly understood and modeled for the accurate simulation of such columns under seismic loading. This paper presents an improved cyclic stress-strain model for FRP-confined concrete on the basis of a critical assessment of an earlier model proposed by Lam and Teng in 2009 by making use of a database containing new test results of both concrete-filled FRP tubes (CFFTs) and concrete cylinders confined with an FRP wrap. The assessment reveals several deficiencies of Lam and Teng's model due to the limited test results available to them. The proposed model corrects these deficiencies and is shown to provide reasonably accurate predictions for both concrete in CFFTs and concrete confined with an FRP wrap and for both normal strength concrete (NSC) and high strength concrete (HSC).

Keywords: FRP; confinement; concrete; stress-strain model; cyclic loading; high-strength concrete

\footnotetext{
${ }^{1}$ Senior Lecturer, School of Civil, Mining and Environmental Engineering, Faculty of Engineering and Information Sciences, University of Wollongong, Northfields Avenue, Wollongong, NSW 2522, Australia (Corresponding author). Tel: +61 242213786 Email: taoy@uow.edu.au

${ }^{2}$ Former PhD Student, Department of Civil and Environmental Engineering, The Hong Kong Polytechnic University, Hong Kong, China.

${ }^{3}$ Chair Professor of Structural Engineering, Department of Civil and Environmental Engineering, The Hong Kong Polytechnic University, Hong Kong, China.
} 
Fiber reinforced polymer (FRP) wraps with fibers oriented completely or predominantly in the hoop direction have been widely used in practice to strengthen/retrofit concrete columns [1,2]. As a result of FRP confinement, both the compressive strength and the ultimate compressive strain of concrete can be significantly enhanced [3,4]. The use of FRP as a confining material has also been explored in new construction, where FRP is typically adopted in the form of a tube to confine the concrete infill with or without additional steel reinforcement (i.e. concrete-filled FRP tubes or CFFTs) [5-7]. In both types of applications, the stress-strain behavior of the FRP-confined concrete needs to be properly understood and modeled before a safe and economical design approach can be developed. The stress-strain behavior of FRP-confined concrete under cyclic axial compression is of particular importance for the accurate modeling of such columns under seismic loading.

A number of experimental studies [8-16] have been conducted on the cyclic stress-strain behavior of concrete confined with an FRP wrap [17]. More recently, the authors' group has conducted the first systematic experimental study on the cyclic compressive behavior of CFFTs [18], where the cyclic stress-strain behavior of the confined concrete was a focus of the study. Zhang et al.'s study [18] showed that the cyclic axial stress-strain behavior of concrete in CFFTs is generally similar to that of concrete confined with an FRP wrap, suggesting that a cyclic stress-strain model for the confined concrete suitable for both types of applications can be developed.

Many studies have examined the stress-strain behavior of unconfined and steel-confined concrete under cyclic compression, leading to a number of cyclic stress-strain models (e.g. [19-21]). These models, however, are generally not applicable to FRP-confined concrete 
47 which is different from unconfined- and steel-confined concretes in nature: the lateral confining pressure does not exist for unconfined concrete and is constant for steel-confined concrete after the yielding of steel, but increases continuously with the lateral deformation of concrete for FRP-confined concrete [22]. To the best of the authors' knowledge, only five cyclic stress-strain models have been proposed for FRP-confined concrete in circular columns (i.e. concrete under uniform FRP confinement) [10,16,17,23,24]. Shao et al.'s model [10] was shown to be inadequate in predicting unloading paths and incapable of predicting the cumulative effect of loading history on the stress-strain response of concrete [11]. Wang et al.'s model [23] is for FRP-confined concrete as well as concrete subjected to combined confinement from FRP and hoop steel reinforcement; this model also does not consider the cumulative effect of repeated loading cycles. Desprez et al.'s model [24] was neither based on test results from cyclic axial compression tests of FRP-confined concrete columns, nor verified directly against such test results. Lam and Teng's model [17] was based on a test database assembled by them and was shown to capture all the key characteristics of and provide reasonably accurate predictions for cyclically loaded FRP-confined concrete. Bai et al.'s model [16] is specifically for concrete confined with FRP possessing a large rupture strain (around 6\%); it includes most of the components (e.g. unloading/reloading paths) of Lam and Teng's model [17] but a different envelope stress-strain curve to reflect the effect of this special type of FRP.

Although Lam and Teng's model [17] was developed on the basis of a relatively large database, a few significant issues could not be readily resolved using the test database available to them at that time. The test database was limited to concrete confined with an FRP wrap. The calibration of the model for high strength concrete (HSC) was based on limited test data from one single study (i.e. Ref. [8]). A recent study by Ozbakkaloglu and Akin [13] has, 
however, shown that the performance of Lam and Teng's model [17] for HSC is not as good as its performance for normal strength concrete (NSC). In addition, while Lam and Teng [17] has considered the cumulative effect of loading history in their model, their proposed equations were based on limited test data with the maximum number of repeated loading cycles at a given unloading point being three.

Against this background, this paper presents a critical assessment of Lam and Teng's model [17] against the new test results of CFFTs obtained by the present authors [18] as well as those of concrete confined with an FRP wrap which were published after Lam and Teng's study [17]. An improved cyclic stress-strain model is then proposed on the basis of this assessment for FRP-confined concrete in circular columns (i.e. concrete under uniform FRP confinement). The proposed model is a unified model in two senses: (1) it is applicable to both concrete confined with an FRP wrap and concrete in CFFTs; (2) it is applicable to both FRP-confined NSC and HSC. This paper is concerned only with concrete confined with conventional FRP (e.g. glass FRP and carbon FRP) with a rupture strain less than 3\%, so Bai et al.'s work [16] is not further discussed in the paper.

\section{TEST DATABASE}

In the present study, a test database was assembled from the studies of Rousakis [8], Ilki and Kumbasar [9], Lam et al. [11], Ozbakkaloglu and Akin [13], Wang et al. [23] and Zhang et al. [18]. Test results from the first three studies were also used by Lam and Teng [17] for the development of their cyclic stress-strain model. Except for Zhang et al. [18] where CFFTs with a filament-wound FRP tube were tested, all the tests were conducted on circular solid cylinders confined with an FRP wrap. The present paper is concerned with concrete confined 
with FRP only, so the majority of the specimens reported in Ref. [23], which had transverse steel reinforcement, are excluded from the test database. Key information of the tests is given in Table 1, while readers may refer to the original papers for more details. In Table 1, the thickness given for wet-layup FRP wraps is the nominal thickness, while that for filament-FRP tubes is the actual thickness; their respective elastic moduli are both based on the thicknesses listed in Table 1. The compressive strength of unconfined concrete was obtained from accompanying compression tests on standard plain concrete cylinders, except for the tests of Rousakis [8], for which the unconfined concrete strengths shown in Table 1 were converted from the cube compressive strength data based on the relationships specified in the CEB-FIP Model Code [25].

All specimens were subjected to a single unloading/reloading cycle at each prescribed unloading displacement/load level except two specimens tested by Lam et al. [11] and six specimens tested by Zhang et al. [18]. As indicated in Table 1, the two specimens (i.e., specimens CI-RC and CII-RC) tested by Lam et al. [11] were subjected to 3 unloading/reloading cycles at each prescribed unloading displacement level and the six specimens tested by Zhang et al. [18] were subjected to 9 12 unloading/reloading cycles at a prescribed unloading displacement level.

Linear variable displacement transducers (LVDTs) were used to obtain axial strains in all the studies. For the specimens in Refs. [8, 9, 13, 18], LVDTs were used to measure the total axial shortenings of specimens; for the specimens in Ref. [11], the LVDTs covered the $120 \mathrm{~mm}$ 
mid-height region of specimens; for the specimens in Ref. [23], the LVDTs covered the 204 mm mid-height region. It has been shown that the strains obtained from total axial shortenings are generally similar to but slightly larger than those obtained from LVDTs covering a certain length of the mid-height region [11, 18], especially in the initial stage of loading, but this effect is generally very small for the later loading stage. Lam and Teng [17] also found that their model was generally applicable to the test database assembled by them despite the different methods of obtaining axial strains.

\section{CYCLIC AXIAL STRESS-STRAIN MODEL}

\subsection{General}

In this section, Lam and Teng's cyclic stress-strain model [17] is first critically assessed against the test data of the new database as described above, with the focus being on its applicability to HSC and concrete in CFFTs. The key components of Lam and Teng's model [17] are examined separately, based on which revisions are proposed, leading to an improved stress-strain model.

\subsection{Key Characteristics of FRP-Confined Concrete}

Lam and Teng's model [17] was proposed based on and can capture the following key characteristics of the experimental cyclic stress-strain behaviour of concrete confined with an FRP wrap: (1) the envelope curve is basically the same as the monotonic stress-strain curve; (2) the loading history has a cumulative effect on both the plastic strain and stress deterioration; (3) the unloading path is generally nonlinear with a continuously decreasing slope while the reloading path is approximately linear. It is shown in Ref. [18] that the cyclic stress-strain behaviour of concrete (including HSC) in CFFTs also possesses the same three 
characteristics, suggesting that the framework of Lam and Teng's model [17] can be retained in developing an improved stress-strain model.

\subsection{Terminology}

The cyclic stress-strain history consists of unloading curves and reloading curves. The unloading curves are defined as the paths that the concrete experiences when its strain reduces. Unloading paths can be further divided into envelope unloading paths (i.e. unloading paths starting from the envelope curve) and internal unloading paths (i.e. the previous reloading path does not reach the envelope curve). They should be both independent of the subsequent terminating point. However, internal unloading paths are dependent on the prior loading history. The stress and strain where an unloading curve starts are named the unloading stress $\sigma_{u n}$ and the unloading strain $\varepsilon_{u n}$ respectively. For envelope unloading, the two terms are denoted by $\sigma_{u n, e n v}$ and $\varepsilon_{u n, e n v}$ respectively. The strain value at the intersection of an unloading path with the strain axis is defined as the plastic strain $\varepsilon_{p l}$. The reloading curves are defined as the paths that the concrete experiences when its strain increases. Similar to unloading paths, reloading paths are also independent of the subsequent terminating point where the concrete once again starts to unload or the concrete reaches the envelope curve. The stress and strain where a reloading curve starts are named the reloading stress $\sigma_{r e}$ and the reloading strain $\varepsilon_{r e}$ respectively. The stress and strain where a reloading curve meets with the corresponding envelope curve are referred as envelope returning stress $\sigma_{r e t, e n v}$ and strain $\varepsilon_{r e t, e n v}$ respectively.

The internal cycles which are defined as those repeated within the envelope curve need to be numbered so that the effects resulting from previous internal cycles on subsequent cycles can be considered. Envelope unloading is always regarded as the first cycle (i.e. $n=1$ ). When 
the subsequent unloading stress is not greater than the present envelope unloading stress $\sigma_{u n, e n v}$, the cycle number needs to be updated (i.e. $n=n+1$ ). The number will be reset to zero when a subsequent unloading stress is greater than this envelope unloading stress $\sigma_{\text {un,env }}$. It is possible to encounter an unloading stress which is larger than the corresponding envelope unloading stress $\sigma_{u n, e n v}$, but is smaller than the envelope returning stress $\sigma_{\text {ret,env }}$. Unloading from such an unloading stress is treated as an envelope unloading cycle following Ref. [17].

The definitions of $\sigma_{u n}, \varepsilon_{u n}, \sigma_{u n, e n v}, \varepsilon_{u n, e n v}, \varepsilon_{p l}, \sigma_{r e}, \varepsilon_{r e}, \sigma_{r e t, e n v}$ and $\varepsilon_{r e t, e n v}$ for both envelope and internal cycles are illustrated in Fig.1.

\subsection{Monotonic Stress-Strain Model for the Envelope Curve}

In Lam and Teng’s model [17], Lam and Teng’s monotonic stress-strain model [22] was adopted to predict the envelope curve of FRP-confined concrete under cyclic compression. A refined version of this design-oriented model was proposed by Teng et al. [26], which includes more accurate expressions for the ultimate axial strain and the compressive strength. Zhang et al. [18] showed that Teng et al.'s model [26] can provide accurate predictions for envelope stress-strain curves of concrete in CFFTs. Teng et al.'s model [26] is therefore adopted in the present stress-strain model for the envelope curve.

Teng et al.'s model [26] consists of a parabolic first portion plus a linear second portion with a smooth transition at $\varepsilon_{t}$, and is described as follows:

$$
\sigma_{c}=E_{c} \varepsilon_{c}-\frac{\left(E_{c}-E_{2}\right)^{2}}{4 f_{c o}^{\prime}} \varepsilon_{c}^{2} \quad \text { for } 0 \leq \varepsilon_{c} \leq \varepsilon_{t}
$$

and 


$$
\sigma_{c}=\left\{\begin{array}{cl}
f_{c o}^{\prime}+E_{2} \varepsilon_{c} & \rho_{K} \geq 0.01 \\
f_{c o}^{\prime}-\frac{f_{c o}^{\prime}-f_{c u}^{\prime}}{\varepsilon_{c u}-\varepsilon_{c o}}\left(\varepsilon_{c}-\varepsilon_{c o}\right) & \rho_{K}<0.01
\end{array} \quad \text { for } \varepsilon_{t}<\varepsilon_{c} \leq \varepsilon_{c u}\right.
$$

190

191

192

193

194

195

$$
\varepsilon_{t}=\frac{2 f_{c o}^{\prime}}{E_{c}-E_{2}}
$$

The compressive strength $f_{c c}^{\prime}$ and ultimate axial strain $\varepsilon_{c u}$ of FRP-confined concrete are 197 defined by:

$$
\frac{f_{c c}^{\prime}}{f_{c o}^{\prime}}=\left\{\begin{array}{cc}
1+3.5\left(\rho_{K}-0.01\right) \rho_{\varepsilon} & \rho_{K} \geq 0.01 \\
1 & \rho_{K}<0.01
\end{array}\right.
$$

198 and

$$
\frac{\varepsilon_{c u}}{\varepsilon_{c o}}=1.75+6.5 \rho_{K}^{0.8} \rho_{\varepsilon}^{1.45}
$$

199 The ratio between the confining pressure $f_{l}$ (the pressure provided by the FRP jacket when it 200 fails by rupture due to hoop tensile stresses) and the unconfined concrete strength $f_{c o}^{\prime}$ is 201 referred as the confinement ratio. The confinement ratio $f_{l} / f_{c o}^{\prime}$ can be expressed as the 202 product of the confinement stiffness ratio $\rho_{K}$ and the strain ratio $\rho_{\varepsilon}$ as shown follows:

$$
\frac{f_{l}}{f_{c o}^{\prime}}=\frac{E_{f r p} t_{f r p} \varepsilon_{h, r u p}}{f_{c o}^{\prime} R}=\rho_{K} \rho_{\varepsilon}
$$




$$
\rho_{K}=\frac{E_{f r p} t_{f r p}}{\left(f_{c o}^{\prime} / \varepsilon_{c o}\right) R}
$$

204

$$
\rho_{\varepsilon}=\frac{\varepsilon_{h, \text { rup }}}{\varepsilon_{c o}}
$$

205

206

207

208

209

210

211

212

213

214

215

$$
\sigma_{c}=a \varepsilon_{c}^{\eta}+b \varepsilon_{c}+c
$$

216 with

$$
a=\frac{\sigma_{u n}-E_{u n, 0}\left(\varepsilon_{u n}-\varepsilon_{p l}\right)}{\varepsilon_{u n}^{\eta}-\varepsilon_{p l}^{\eta}-\eta \varepsilon_{p l}^{\eta-1}\left(\varepsilon_{u n}-\varepsilon_{p l}\right)}
$$

217

$$
b=E_{u n, 0}-\eta \varepsilon_{p l}^{\eta-1} a
$$

218

$$
c=-a \varepsilon_{p l}^{\eta}-b \varepsilon_{p l}
$$

219

$$
\eta=350 \varepsilon_{u n}+3
$$




$$
E_{u n, 0}=\min \left(\frac{0.5 f_{c o}^{\prime}}{\varepsilon_{u n}}, \frac{\sigma_{u n}}{\varepsilon_{u n}-\varepsilon_{p l}}\right)
$$

221 in which, $\sigma_{c}$ and $\varepsilon_{c}$ are the axial stress and axial strain of concrete respectively; and $E_{u n, 0}$

222 is the slope of the unloading path at zero stress (Fig.1).

Fig. 2 shows a comparison between the predictions of the above equations and the experimental envelope unloading curves from Ref. [18]. In making the predictions, the experimental $\varepsilon_{u n}, \sigma_{u n}$ and $\varepsilon_{p l}$ were used so that the comparison in Fig. 2 reflects only the performance of the equations for the unloading path (i.e. Eqs. 11-16). Fig. 2 shows that Eqs. 11-16 provide reasonably accurate predictions for specimens S54-2FW-C1 and S54-4FW-C1, but the predictions deviate significantly from the experimental results for the remaining specimens which had higher unconfined strengths. This observation suggests that Lam and Teng's model [17] may be applicable to FRP-confined NSC, but revisions are needed before Lam and Teng's model [17] can accurately predict the unloading paths of FRP-confined HSC. This is probably due to the fact that the development of Lam and Teng's model [17] relied heavily on the experimental results by Lam et al. [11] which only covered a small range of concrete strengths (i.e. 38.9 MPa and 41.1 MPa).

In Lam and Teng's model [17], two parameters are used to control the shape of the unloading path: (1) parameter $\eta$ which controls the rate of change in the degree of non-linearity (or the curvature) of an unloading path with the unloading strain; (2) parameter $E_{u n, 0}$ which controls the slope of the unloading path at zero stress. Lam and Teng [17] proposed Eq. 16 for $E_{u n, 0}$ where the unconfined concrete strength $f_{c o}^{\prime}$ is already a parameter. Fig. 3 compares the predictions of Eq. 16 with the experimental results, and demonstrates its applicability to HSC. The inaccuracy of Lam and Teng's model [17] for HSC is therefore 
244 believed to be mainly due to their equation for $\eta$ (i.e. Eq. 15) which does not reflect the 245 effect of unconfined concrete strength $f_{c o}^{\prime}$. Based on the experimental results in Ref. [18], the 246 following equation was derived through a trial and error process, with $f_{c o}^{\prime}$ being an 247 additional controlling parameter:

$$
\eta=40\left(350 \varepsilon_{u n}+3\right) / f_{c o}^{\prime}
$$

248

Eq. 17 reduces to Eq. 15 when $f_{c o}^{\prime}$ is equal to $40 \mathrm{MPa}$. Fig. 2 shows that the use of the new equation leads to much better predictions than the use of Eq. 15 in Ref. [17], especially for specimens S84-4FW-C, S84-9FW-C, S104-4FW-C1 and S104-9FW-C.

\subsection{Plastic Strain of Envelope Cycles}

Lam and Teng [17] proposed the following equation to predict the plastic strain of envelope unloading curves $\varepsilon_{p l, 1}$, where the unconfined concrete strength $f_{c o}^{\prime}$ and the envelope unloading strain $\varepsilon_{u n, e n v}$ are the two controlling parameters:

$\varepsilon_{p l, 1}$

$=\left\{\begin{array}{cc}0 & 0<\varepsilon_{u n, e n v} \leq 0.001 \\ {\left[1.4\left(0.87-0.004 f_{c o}^{\prime}\right)-0.64\right]\left(\varepsilon_{u n, e n v}-0.001\right)} & 0.001<\varepsilon_{u n, e n v}<0.0035 \\ \left(0.87-0.004 f_{c o}^{\prime}\right) \varepsilon_{u n, e n v}-0.0016 & 0.0035 \leq \varepsilon_{u n, e n v} \leq \varepsilon_{c u}\end{array}\right.$

In Ref. [17], the development of Eq. 18 was based on: (1) the experimental observation that the plastic strain is independent of the confinement level and has a linear relationship with the envelope unloading strain; (2) the limited test results by Rousakis [8], Ilki and Kumbasar [9] and Lam et al. [11] among which only Rousakis's study [8] covered HSC. While the first observation has been continuously supported by new test results [13, 23], a recent experimental study on FRP-confined HSC by Ozbakkaloglu and Akin [13] suggested that the unconfined concrete strength does not appear to have a considerable effect on the envelope plastic strain. Ozbakkaloglu and Akin [13] also showed that Eq. 18 provides reasonably accurate predictions for their test results on NSC, but underestimates the plastic strain of 
envelope unloading curves $\varepsilon_{p l, 1}$ significantly based on their test results for HSC.

To clarify this issue, the plastic strains obtained from Ref. [18] are shown against the corresponding envelope unloading strains in Fig. 4, where the trend lines for $\varepsilon_{\text {un,env }}>$ 0.0035 are also shown. Table 2 summarizes the statistical characteristics of the trend lines for specimens in Table 1 including the three studies used in Ref. [17]. Fig. 4 confirms the linear relationship between the plastic strain $\varepsilon_{p l, 1}$ and the envelope unloading strain $\varepsilon_{u n, e n v}$. Table 2, however, suggests that such a linear relationship is not significantly affected by the unconfined concrete strength. The coefficient $a$ (i.e. the slope of the trend line) is further shown against the unconfined concrete strength in Fig. 5, which clearly indicates that this coefficient is similar for most specimens covering a range of unconfined concrete strength from 24.5 MPa to $105 \mathrm{MPa}$. The only exceptions appear to be the three HSC specimens tested by Rousakis [8] which had a lower $a$ value. It should be noted that these three specimens were also the only HSC specimens used in Ref. [17] in developing Eq. 18, which includes the unconfined concrete strength as a controlling parameter. For further comparison, present study.

Based on the experimental results summarized in Table 2, the following equations are proposed for the plastic strain of envelope curves, where the unconfined strength is not used as a parameter:

$$
\varepsilon_{p l, 1}=\left\{\begin{array}{cc}
0 & 0<\varepsilon_{\text {un,env }} \leq 0.001 \\
0.184 \varepsilon_{\text {un,env }}-0.0002 & 0.001<\varepsilon_{u n, e n v} \leq 0.0035 \\
0.703 \varepsilon_{u n, e n v}-0.002 & 0.0035<\varepsilon_{\text {un,env }} \leq \varepsilon_{c u}
\end{array}\right.
$$

287 In the development of Eq. 19, the two coefficients $a$ and $b$ are obtained by averaging the $a$ 

301

$$
\phi_{1}=\left\{\begin{array}{cc}
1 & 0<\varepsilon_{u n, e n v} \leq 0.001 \\
1-80\left(\varepsilon_{u n, e n v}-0.001\right) & 0.001<\varepsilon_{u n, e n v}<0.002 \\
0.92 & 0.002 \leq \varepsilon_{\text {un }, \text { env }} \leq \varepsilon_{c u}
\end{array}\right.
$$
reasonably accurate predictions for the majority of the test results and is far superior to Eq. 18 proposed by Lam and Teng [17]. It should be noted that Eq. 19 implies that $\varepsilon_{p l, 1}$ is observation [e.g. the $4^{\text {th }}$ unloading curve of specimen S54-4FW-C1 and the $6^{\text {th }}$ unloading curve of specimen S54-2FW-C1 have similar envelope unloading strains but quite different unloading stresses, and they also have similar plastic strains (see Fig. 2)].

\subsection{Stress Deterioration of Envelope Cycles}

It has been commonly observed (e.g. Ref. [11]) that the new stress $\sigma_{\text {new, } 1}$ on the first reloading path at the envelope unloading strain is lower than the envelope unloading stress. This phenomenon is referred to as stress deterioration. Lam and Teng [17] proposed the following equations for the stress deterioration ratio $\phi_{1}$ of envelope cycles:

and $b$ values listed in Table 2 for all the specimens. Fig. 6(b) shows that Eq. 19 can provide independent of the unloading stress, which is also consistent with the experimental

where $\phi_{1}$ is defined as

$$
\phi_{1}=\frac{\sigma_{\text {new }, 1}}{\sigma_{u n, e n v}}
$$

The performance of Eq. 20 is shown in Fig. 7 against the experimental results from Ref. [18] and two other studies published after Ref. [17]. Fig. 7 shows that Eq. 20 provides reasonably accurate predictions except for the envelope unloading strains $\varepsilon_{u n, e n v}$ which are between 0.001 and 0.035 . For this range of $\varepsilon_{\text {un,env }}$, the predictions of Eq. 20 appear to be on the lower bound. In order to address this deficiency of Eq. 20, the following equations are proposed based on all the available test data: 


$$
\phi_{1}=\left\{\begin{array}{cc}
1 & 0<\varepsilon_{u n, e n v} \leq 0.001 \\
1-32\left(\varepsilon_{u n, e n v}-0.001\right) & 0.001<\varepsilon_{u n, e n v} \leq 0.0035 \\
0.92 & 0.0035<\varepsilon_{u n, \text { env }} \leq \varepsilon_{c u}
\end{array}\right.
$$

The predictions of Eq. 22 are shown to be better than Lam and Teng's equation [17], especially for the cases where $0.001<\varepsilon_{\text {un,env }} \leq 0.0035$ (Fig. 7). The use of 0.0035 instead of 0.002 as a threshold is also consistent with the equation for the plastic strain (i.e. Eq. 19).

\subsection{Effect of Loading History}

It is evident from Ref. [11] on concrete confined with an FRP wrap and the new test results from Ref. [18] on CFFTs that the loading history has a cumulative effect on both the plastic strain and stress deterioration. The cumulative effect of loading history is considered in Lam and Teng's model [17], but their proposed equations were based on only data from Ref. [11] where the maximum number of repeated loading cycles at a given unloading point was three. In this section, Lam and Teng's equations [17] are evaluated against new test results from Ref. [18] where the maximum number of repeated loading cycles ranged from 9 to 12. Revisions to Lam and Teng's equations [17] are then proposed wherever necessary.

\subsubsection{Partial unloading and reloading}

In some cases, an unloading curve is terminated before reaching the zero stress point, or a reloading curve is terminated before reaching the reference strain (defined in Eq. 25, normally equal to the envelope unloading strain). These cases are referred to as partial unloading and partial reloading respectively. In the present study, the following definitions for the partial unloading factor $\beta_{u n, n}$ and the partial reloading factor $\gamma_{r e, n}$ are used to consider the effect of partial unloading/reloading, following Ref. [17]: 


$$
\begin{array}{ll}
\beta_{u n, 1}=\frac{\sigma_{u n, e n v}-\sigma_{r e, 1}}{\sigma_{u n, e n v}} & \mathrm{n}=1 \\
\beta_{u n, n}=\frac{\sigma_{u n, n}-\sigma_{r e, n}}{\sigma_{n e w, n-1}} & \mathrm{n} \geq 2
\end{array}
$$

331

$$
\gamma_{r e, n}=\frac{\varepsilon_{u n, n+1}-\varepsilon_{p l, n}}{\varepsilon_{r e f, n}-\varepsilon_{p l, n}} \quad(\mathrm{n}=1,2,3, \ldots)
$$

332 where $\varepsilon_{u n, n}, \sigma_{u n, n}, \varepsilon_{p l, n}$ and $\sigma_{\text {new,n }}$ are the unloading strain, unloading stress, plastic 333 strain, new stress at the reference strain of the $n^{\text {th }}$ loading cycle respectively; the reference 334 strain point is defined by:

$$
\begin{array}{cc}
\varepsilon_{r e f, 1}=\varepsilon_{u n, e n v} & \mathrm{n}=1 \\
\varepsilon_{r e f, n}=\max \left(\varepsilon_{r e f, n-1}, \varepsilon_{u n, n}\right) & \mathrm{n} \geq 2
\end{array}
$$

335

$$
\begin{aligned}
& \sigma_{\text {ref }, 1}=\sigma_{\text {un,env }} \quad \mathrm{n}=1 \\
& \sigma_{r e f, n}=\left\{\begin{array}{cl}
\sigma_{r e f, n-1} & \varepsilon_{u n, n} \leq \varepsilon_{\text {ref }, n-1} \\
\sigma_{u n, n} & \varepsilon_{u n, n}>\varepsilon_{\text {ref }, n-1}
\end{array} \quad \mathrm{n} \geq 2\right.
\end{aligned}
$$

336 The following conditions proposed by Lam and Teng [17] for effective unloading/reloading 337 cycles are also adopted in the present study:

$$
\beta_{u n} \geq 0.7 \text { and } \gamma_{r e} \geq 0.7
$$

338

\subsubsection{Plastic strain of internal cycles}

340 Lam and Teng [17] proposed the following equations for plastic strains of internal cycles:

$$
\omega_{n}=\frac{\varepsilon_{u n, n}-\varepsilon_{p l, n}}{\varepsilon_{u n, n}-\varepsilon_{p l, n-1}} \quad \mathrm{n} \geq 2
$$

341

$$
\omega_{n}=\min \left\{\begin{array}{c}
1 \\
\omega_{n, f u l}-0.25\left(\gamma_{r e, n-1}-1\right)
\end{array} \mathrm{n} \geq 2\right.
$$




$$
\begin{aligned}
& \omega_{n, f u l}\left(2 \leq n_{e} \leq 5\right) \\
& =\left\{\begin{array}{cc}
1+400\left(0.0212 n_{e}-0.12\right)\left(\varepsilon_{u n, e n v}-0.001\right) & 0.001<\varepsilon_{u n, e n v} \leq 0.001 \\
0.0212 n_{e}+0.88 & 0.0035 \leq \varepsilon_{u n, e n v}<0.0035
\end{array}\right. \\
&
\end{aligned}
$$

343 in which $\varepsilon_{u n, n}$ and $\varepsilon_{p l, n}$ are the unloading strain and plastic strain of the $n^{\text {th }}$ loading cycle 344 respectively from an envelope unloading strain $\varepsilon_{u n, e n v}$, with $\mathrm{n}=1$ representing the envelope cycle; $\omega_{n}$ is the strain recovery ratio; $\omega_{n, f u l}$ is the strain recovery ratio for the case of $\gamma_{r e, n-1}=1$ (i.e. full reloading); and $n_{e}$ is the number of effective cycles. Lam and Teng [17] proposed that Eq. 30 is only applicable when $2 \leq n_{e} \leq 5$, and that $\omega_{n, f u l}=1$ when $n_{e} \geq 6$.

The predictions of Eq. 30 are compared with the new test results of Ref. [18] in Fig. 8. The test results presented in Ref. [11] are also shown in Fig. 8 for comparison. Fig. 8 shows that Eq. 30 generally provides reasonably accurate predictions when $n_{e}<5$ for both concrete confined with an FRP wrap and concrete in CFFTs, but overestimates the test results when the maximum $n_{e}$ being 3. In order to address this deficiency of Lam and Teng's model [17],

$$
\begin{aligned}
& \omega_{n, f u l}\left(n_{e} \geq 2\right) \\
& =\left\{\begin{array}{cc}
1 & 0<\varepsilon_{u n, e n v} \leq 0.001 \\
1-32\left(\varepsilon_{u n, e n v}-0.001\right) /\left(n_{e}-1\right) & 0.001<\varepsilon_{u n, e n v} \leq 0.0035 \\
-0.08 /\left(n_{e}-1\right)+1 & 0.0035<\varepsilon_{u n, e n v} \leq \varepsilon_{c u}
\end{array}\right.
\end{aligned}
$$


cycles:

$$
\phi_{n}=\frac{\sigma_{n e w, n}}{\sigma_{r e f, n}}
$$

362

$$
\phi_{n}=\min \left\{\begin{array}{cc}
1 & \mathrm{n} \geq 2 \\
\phi_{n, f u l}-0.2\left(\beta_{u n, n}-1\right) &
\end{array}\right.
$$

363

$$
\begin{aligned}
& \phi_{n, f u l}\left(2 \leq n_{e} \leq 5\right) \\
& =\left\{\begin{array}{cc}
1+1000\left(0.013 n_{e}-0.075\right)\left(\varepsilon_{u n, e n v}-0.001\right) & 0.001<\varepsilon_{u n, e n v} \leq 0.001 \\
0.013 n_{e}+0.925 & 0.002 \leq \varepsilon_{u n, e n v}<0.002
\end{array}\right. \\
&
\end{aligned}
$$

364 in which $\phi_{n}$ is the stress deterioration ratio of the $n^{\text {th }}$ loading cycle from an envelope 365 unloading strain $\varepsilon_{u n, e n v} ; \phi_{n, f u l}$ is the stress deterioration ratio for the case of $\beta_{u n, n}=1$. 366 Lam and Teng [17] proposed Eq. 34 for use when $2 \leq n_{e} \leq 5$, and that $\phi_{n, f u l}=1$ when $367 \quad n_{e} \geq 6$

The predictions of Eq. 34 are compared with the new test results of Zhang et al. [18] in Fig. 9. The test results presented in Ref. [11] are also shown in Fig. 9 for comparison. Similar to the observation for Lam and Teng’s equations [17] for plastic strains, Eq. 34 generally provides reasonably accurate predictions when $n_{e}<5$, but overestimates the test results when $n_{e} \geq 6$. In order to address this deficiency of Lam and Teng's model [17], the following equations (Eq. 35) are proposed for $\phi_{n, f u l}$ based on regression analysis of the mean $\phi_{n, f u l}$ values from all the available test data:

$$
\phi_{n, f u l}=\left\{\begin{array}{cc}
1 & 0<\varepsilon_{u n, e n v} \leq 0.001 \\
1-80\left(\varepsilon_{u n, e n v}-0.001\right) / n_{e} & 0.001<\varepsilon_{u n, e n v} \leq 0.002 \\
-0.08 / n_{e}+1 & 0.002<\varepsilon_{u n, e n v} \leq \varepsilon_{c u}
\end{array}\right.
$$

\subsection{Reloading Path}

A reloading path is defined as the stress-strain path that the concrete traces as its strain 
increases from a starting point on an unloading path. Lam and Teng [17] proposed equations for the reloading path based on the test observation that the major part of each reloading path of FRP-confined concrete resembles a straight line. In Lam and Teng's model [17], the reloading path consists of a linear first portion from the reloading strain $\varepsilon_{r e}$ to the reference strain $\varepsilon_{r e f}$, and a possible short parabolic portion for the remaining part to meet smoothly with the envelope curve.

The linear portion of the reloading path is defined as follows:

$$
\sigma_{c}=\sigma_{r e}+E_{r e}\left(\varepsilon_{c}-\varepsilon_{r e}\right) \quad \varepsilon_{r e} \leq \varepsilon_{c} \leq \varepsilon_{r e f}
$$

where the slope of the linear portion is found from:

$$
E_{r e}=\left(\sigma_{\text {new }}-\sigma_{r e}\right) /\left(\varepsilon_{r e f}-\varepsilon_{r e}\right) \quad \varepsilon_{r e} \leq \varepsilon_{c} \leq \varepsilon_{r e f}
$$

In most cases, the linear portion is followed by a parabola from the reference strain point to the envelope returning point. In some cases, the reloading path consists of only a straight line that returns to the envelope curve directly at the envelope unloading point. These cases are [17]: (1) $\varepsilon_{u n, e n v} \leq 0.001 ;$ (2) $\mathrm{n}=1 ; \varepsilon_{u n, e n v}>0.001 ; \sigma_{r e, 1}>0.85 \sigma_{u n, e n v}$; and (3) $\mathrm{n}>1$; $\varepsilon_{u n, e n v}>0.001 ; \sigma_{r e, n}>0.85 \sigma_{u n, e n v}$

The parabolic portion of the reloading path is given as follows:

$$
\sigma_{c}=A \varepsilon_{c}^{2}+B \varepsilon_{c}+C \quad \varepsilon_{r e f} \leq \varepsilon_{c} \leq \varepsilon_{r e t, e n v}
$$

For cases where the reloading path returns to the parabolic first portion of the envelope curve, the parameter $\mathrm{A}$ is as follows:

$$
A=\frac{\left(E_{c}-E_{2}\right)^{2}\left(E_{r e} \varepsilon_{r e f}-\sigma_{n e w}\right)+\left(E_{c}-E_{r e}\right)^{2} f_{c o}^{\prime}}{4\left(\sigma_{\text {new }}-E_{c} \varepsilon_{r e f}\right) f_{c o}^{\prime}+\left(E_{c}-E_{2}\right)^{2} \varepsilon_{r e f}^{2}}
$$




$$
\varepsilon_{\text {ret }, e n v}=\frac{E_{c}-B}{2 A+\left(\frac{E_{c}-E_{2}}{f_{c o}^{\prime}}\right)^{2}}<\varepsilon_{t}
$$

398

399 For cases where the reloading path returns to the linear section portion of the envelope curve, 400 the parameter $\mathrm{A}$ is as follows:

$$
A=\frac{\left(E_{r e}-E_{2}\right)^{2}}{4\left(\sigma_{n e w}-f_{c o}^{\prime}-E_{2} \varepsilon_{r e f}\right)} \quad \varepsilon_{r e t, e n v}=\frac{E_{c}-B}{2 A} \geq \varepsilon_{t}
$$

401

402

The other two parameters, B and C, are as follows:

$$
B=E_{r e}-2 A \varepsilon_{r e f}
$$

403

$$
C=\sigma_{\text {new }}-A \varepsilon_{\text {ref }}^{2}-B \varepsilon_{\text {ref }}
$$

404

405

Apparently, the new stress $\sigma_{\text {new }}$, which determines the slope of the linear portion, is a key

406 parameter for the reloading path. Given that $\sigma_{\text {new }}$ is accurately predicted by the new equations proposed in the present study (Eqs. 21-22, 32-33, 35), it is reasonable to expect that Eqs. 36-42 can also provide close predictions for the test results of FRP-confined HSC whose reloading paths also have a major part resembling a straight line. Eqs. 36-42 are therefore adopted in the proposed model.

\subsection{Summary of the Proposed Model}

To summarize, the proposed cyclic stress-strain model for FRP-confined concrete includes generating cyclic stress-strain curves is similar to that explained in Ref. [17]. 


\section{PERFORMANCE OF PROPOSED MODEL}

419 The predictions of the proposed model are compared with the experimental results of Ref. [18] in Fig. 10 for envelope unloading/reloading cycles. The predictions of Lam and Teng's model [17] are also shown for comparison. It is evident that the predictions agree very well with the experimental results in terms of the envelope stress-strain curve, except for the initial slope for some specimens. The difference in the initial slope is due to the use of strains calculated from the total axial shortenings (i.e. LVDT readings) in establishing the experimental curves [18]. As explained in Ref. [18], the strains from LVDTs are generally larger than those at mid-height in the initial stage of loading. If the actual axial strains of concrete at mid-height are used, it can be expected that the predicted initial slopes will be in closer agreement with the experimental results.

It is also evident from Fig. 10 that the proposed model is superior to Lam and Teng's model [17], especially for specimens in the S84 and S104 series. The proposed model generally provides reasonably accurate predictions, but considerable errors are also seen for some specimens (i.e. specimens S84-9FW-C and S104-9FW-C). The errors are found to be mainly from the inaccuracy in predicting the envelope plastic strain $\varepsilon_{p l, 1}$. The equation proposed in the present study (i.e. Eq. 19) for $\varepsilon_{p l, 1}$ is based on a regression analysis of all the available test data while there is considerable scatter in the test data (Fig. 6). When the experimental envelope strains of the three specimens (i.e. specimens S54-2FW-C1, S84-9FW-C and S104-9FW-C) are used, Fig. 11 shows that the proposed model compares very well with the test results and is far superior to Lam and Teng's model [17]. The small error of the proposed model in terms of the predicted reloading path, especially for specimen S84-4FW-C (see Fig. 11), is mainly due to the error in predicting the envelope stress-strain curve, as discussed by Zhang et al. [18]. 
444 Fig. 12 shows comparisons between the experimental results and the predictions of the two models (i.e. the proposed model and Lam and Teng's model [17]) for repeated unloading/reloading cycles. In order to assess these unloading/reloading cycles clearly, each 447 cycle is shown with the corresponding predicted cycle individually to avoid the over-crowding of curves at the same unloading strain. Only the $1^{\text {st }}, 4^{\text {th }}, 7^{\text {th }}$, and the last cycles are examined here. In Fig. 12, the experimental plastic strains of envelope cycles $\varepsilon_{p l, 1}$ are used instead of Eq. 19, in order to eliminate the effect of inaccuracy in this equation. Again, the proposed model is shown to be superior to Lam and Teng's model [17] especially for specimens in the S84 and S104 series, suggesting that the proposed revisions for $\omega_{n, f u l}$ and $\phi_{n, f u l}$ can capture the effect of loading history.

As evident from the development process of the proposed model, the proposed model basically reduces to and provides very similar predictions as Lam and Teng's model [17] with an FRP wrap were tested.

\section{CONCLUSIONS}

An improved cyclic stress-strain model for FRP-confined concrete has been presented in the paper. The development of the proposed model has been based on a critical assessment of Lam and Teng's model [17] by making use of a large test database containing new test results on both concrete in filament-wound FRP tubes and concrete confined with an FRP wrap, which were published after Ref. [17]. The proposed cyclic stress-strain model has the 
following new features:

(1) It provides accurate predictions for the unloading paths of FRP-confined HSC. The degree of non-linearity of unloading paths of FRP-confined HSC is different from that of FRP-confined NSC. This characteristic is considered in the proposed model.

(2) It provides accurate predictions for the plastic strain of FRP-confined HSC. The relationship between the plastic strain $\varepsilon_{p l, 1}$ and the envelope unloading strain $\varepsilon_{u n, e n v}$ does not seem to be significantly affected by the unconfined concrete strength, so a new equation was proposed to capture this observation.

(3) It provides accurate predictions of the effect of repeated loading cycles (i.e. $\omega_{n, f u l}$ and $\left.\phi_{n, f u l}\right)$ based on the large test database.

The proposed cyclic stress-strain model therefore provides reasonably accurate predictions for both NSC and HSC confined with either an FRP wrap or an FRP filament-wound tube.

\section{ACKNOWLEDGEMENTS}

The authors are grateful for the financial support received from the National Basic Research Program of China (i.e. the 973 Program) (Project No.: 2012CB026201), the Research Grants Council of the Hong Kong Special Administrative Region, China (Project No: PolyU 5278/07E) as well as the Australian Research Council through a Discovery Early Career Researcher Award (Project ID: DE140101349) for the first author.

\section{REFERENCES}

[1] Teng, J. G., Chen, J. F., Smith, S. T. and Lam, L. (2002). FRP strengthened RC Structures, Wiley, New York. 
[2] Hollaway, L. C. and Teng, J. G. (2008). Strengthening and Rehabilitation of Civil Infrastructures Using FRP Composites, Woodhead Publishing Limited, Cambridge, U.K.

[3] Lam, L. and Teng, J. G. (2002). "Strength models for fiber-reinforced plastic-confined concrete.” Journal of Structure Engineering, ASCE, 128(5), 612-623.

[4] Teng, J.G. and Lam, L. (2004). "Behavior and modeling of fiber reinforced polymer-confined concrete.” Journal of Structural Engineering, ASCE, 130(11), 1713-1723.

[5] Teng, J. G., Huang, Y. L., Lam, L. and Ye, L. P. (2007). “Theoretical model for fiber reinforced polymer-confined concrete.” Journal of Composites for Construction, ASCE,11(2), 201-210.

[6] Yu, T., and Teng, J.G. (2011). "Design of concrete-filled FRP tubular columns: provisions in the Chinese technical code for infrastructure application of FRP composites”, Journal of Composites for Construction, ASCE, 15(3), 451-461.

[7] Mirmiran, A. (2003). “Stay-in-place FRP form for concrete columns”, Advances in Structural Engineering, 6(3), 231-241.

[8] Rousakis, T. C. (2001). Experimental Investigation of Concrete Cylinders Confined by Carbon FRP Sheets Under Monotonic and Cyclic Axial Compression Load, Research Report 01:2, Division of Building Technology, Chalmers Univ. of Technology, Gothenburg, Sweden.

[9] Ilki, A. and Kumbasar, N. (2003). "Compressive behavior of carbon fiber composite jacketed concrete with circular and non-circular cross sections.” Journal of Earthquake Engineering, 7(3), 381-406.

[10] Shao, Y., Zhu, Z. and Mirmiran, A. (2006). “Cyclic modeling of FRPconfined concrete with improved ductility.” Cement and Concrete Composites, 28(10), 959-968.

[11] Lam, L., Teng, J. G., C.H. Cheung and Y. Xiao (2006). “FRP-confined concrete under 
axial cyclic compression.” Cement \& Concrete Composites, 28, 949-958.

[12] Abbasnia, R. and Ziaadiny, H. (2010). “Behavior of concrete prisms confined with FRP composites under axial cyclic Compression.” Engineering Structures, 32, 648-665.

[13] Ozbakkaloglu, T., and Akin, E.. (2012) "Behavior of FRP-confined normal-and high-strength concrete under cyclic axial compression.” Journal of Composites for Construction, ASCE, 16, 451-463.

[14] Abbasnia, R., Ahmadi, R. and Ziaadiny, H. (2012). "Effect of confinement level, aspect ratio and concrete strength on the cyclic stress-strain behavior of FRP-confined concrete prisms.” Composites Part B: Engineering, 43, 825-831.

[15] Abbasnia, R., Hosseinpour, F., Rostamian, M. and Ziaadiny, H. (2013). “Cyclic and monotonic behavior of FRP confined concrete rectangular prisms with different aspect ratios.” Construction and Building Materials, 40, 118-125.

[16] Bai, Y.L., Dai, J.G. and Teng, J.G. (2014) “Cyclic compressive behavior of concrete confined with large rupture strain FRP composites”, Journal of Composites for Construction, ASCE, 18(1), 04013025.

[17] Lam, L., and Teng, J. G. (2009). “Stress-strain model for FRP-confined concrete under cyclic axial compression.” Engineering Structures, 31(2), 308-321.

[18] Zhang, B., Yu, T. and Teng, J.G. (2014). "Behavior of concrete-filled FRP tubes under cyclic axial compression”, Journal of Composites for Construction, ASCE, 04014060.

[19] Mander, J. B., Priestley, M. J. and Park, R. (1988). “Theoretical stress-strain model for confined concrete”, Journal of Structural Engineering ASCE, 114(8): 1804-1826.

[20] Sinha, B.P., Gerstle, K.H., and Tulin, L.G. (1964) “Stress-strain relations for concrete under cyclic loading”, ACI Journal, 61(2):195211.

[21] Karsan, I.D. and Jirsa, J.O. (1969) “Behavior of concrete under compressive loadings”, 

(2003). “Design-oriented stress-strain model for FRP-confined concrete.” Construction and Building Materials, 17(6-7), 471-489.

[23] Wang, Z.Y., Wang, D.Y., Simth, S.T. and Lu, D.G. (2012). "Experimental testing and analytical modeling of CFRP-confined large circular RC columns subjected to cyclic axial compression”, Engineering Structures, 40, 67-74.

[24] Desprez, C., Mazars, J., Kotronis, P. and Paultre, P. (2013). "Damage model for FRP-confined concrete columns under cyclic loading”, Engineering Structures, 48, 519-531.

[25] CEB-FIP. CEB-FIP Model Code, Comite Euro-International Du Beton. London, (UK): Thomas Telford; 1990.

[26] Teng, J. G., Jiang, T., Lam, L. and Luo, Y. Z. (2009). “Refinement of a design-oriented stress-strain model for FRP-confined concrete.” Journal of Composites for Construction, ASCE, 13(4), 269-278. 


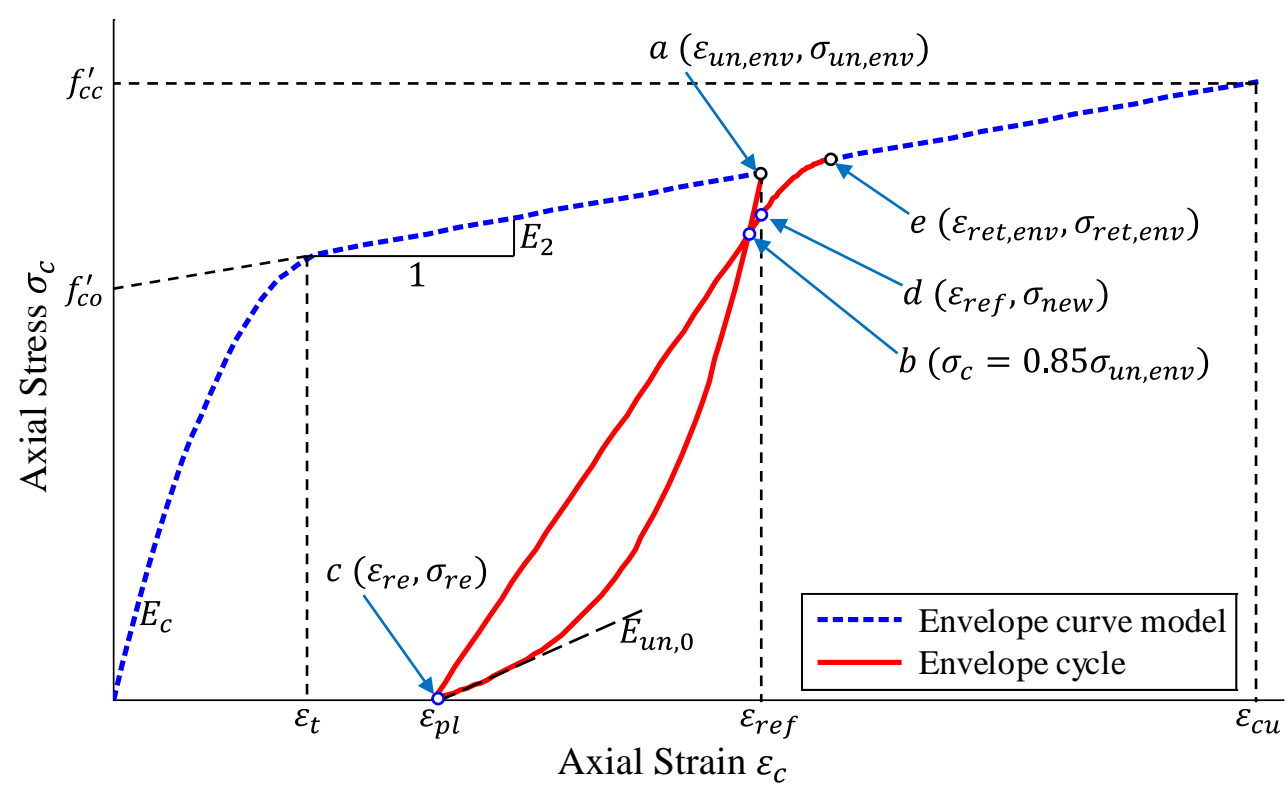

(a) Envelope cycle

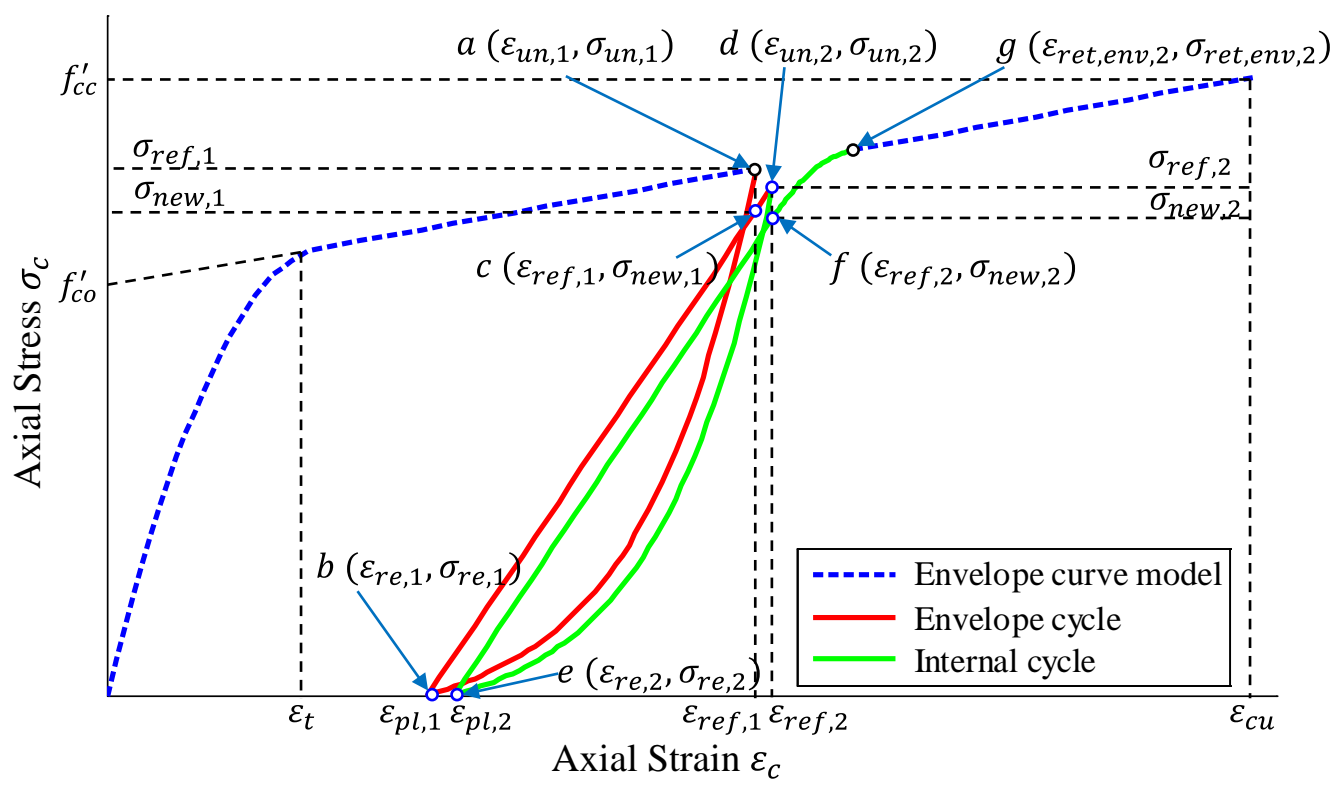

(b) Internal cycles

Figure 1: Key parameters of cyclic stress-strain curves of FRP-confined concrete (After Lam and Teng [17]) 

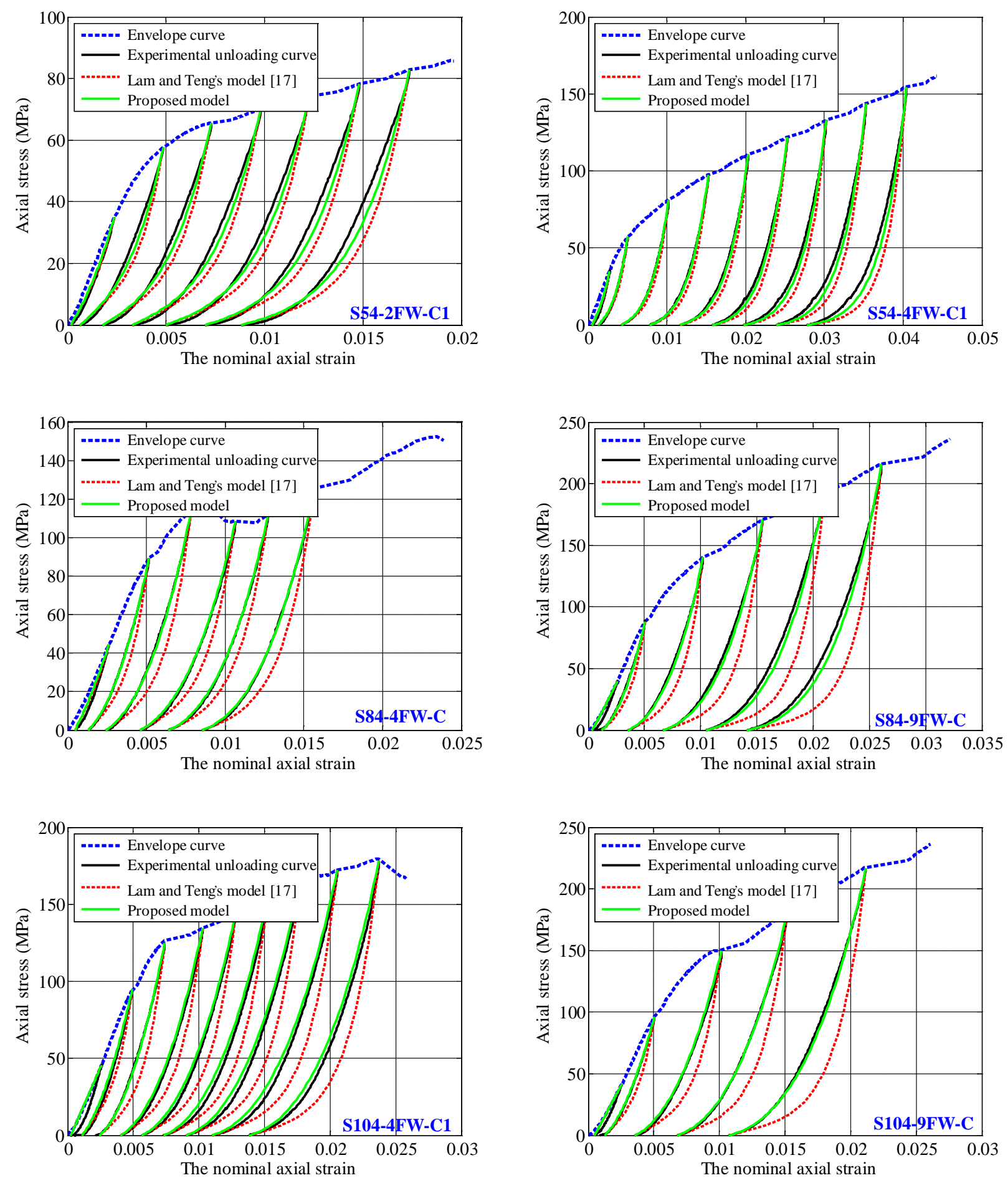

Figure 2: Envelope unloading curves 


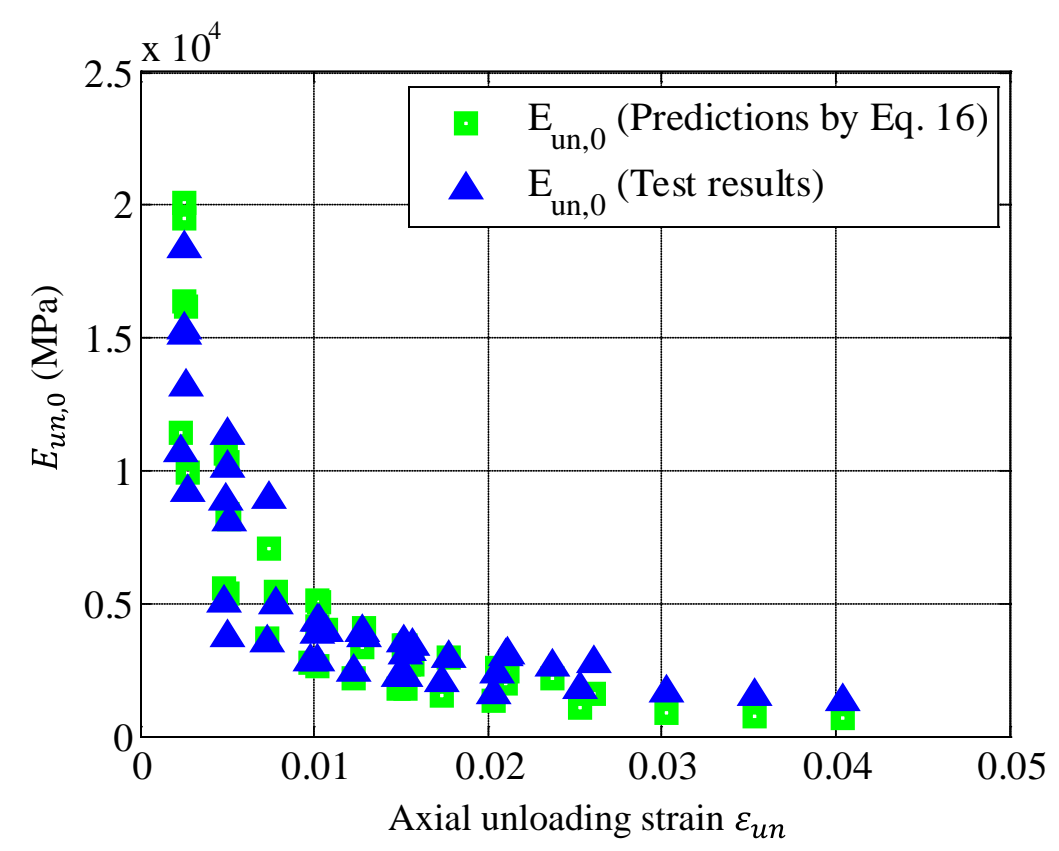

Figure 3: Slope of the unloading path at zero stress
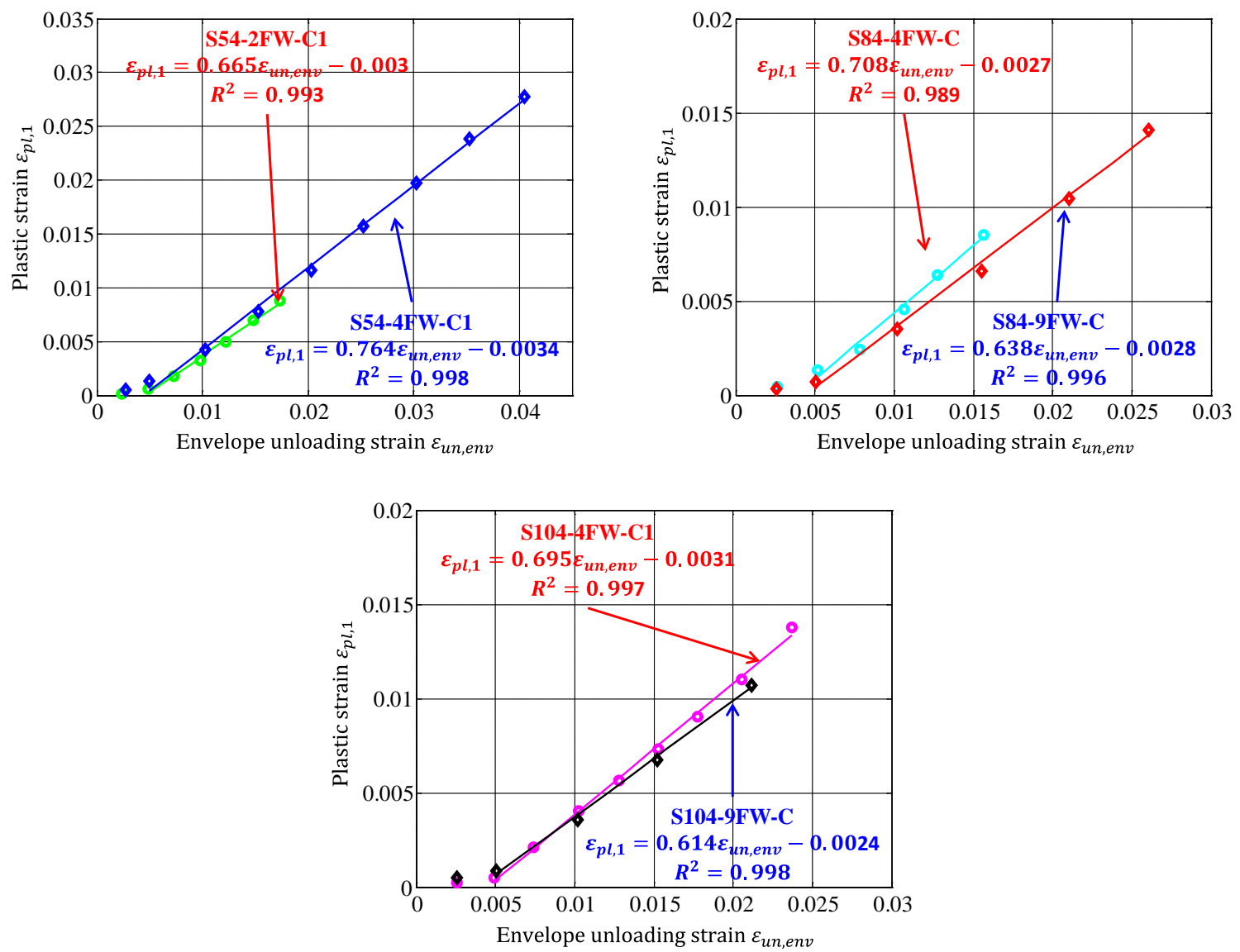

Figure 4: Relationships between plastic strains and envelope unloading strains 


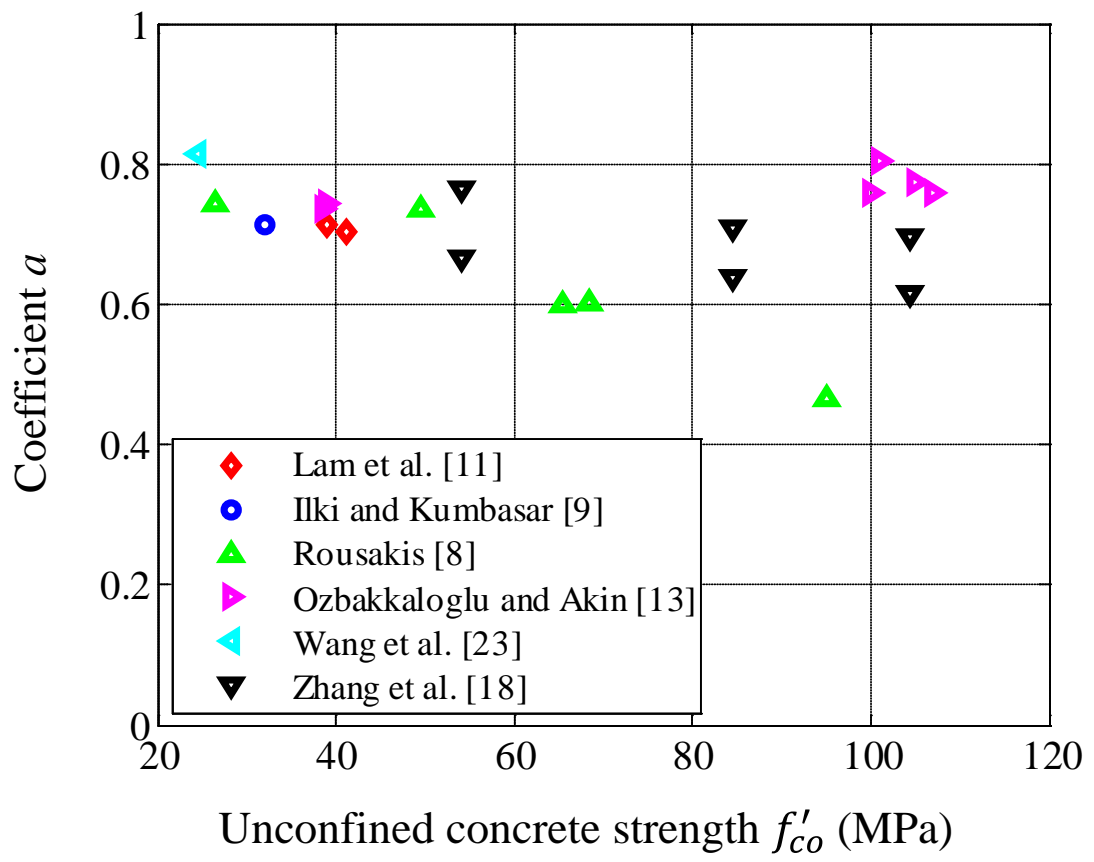

Figure 5: Effect of concrete strength on plastic strain 


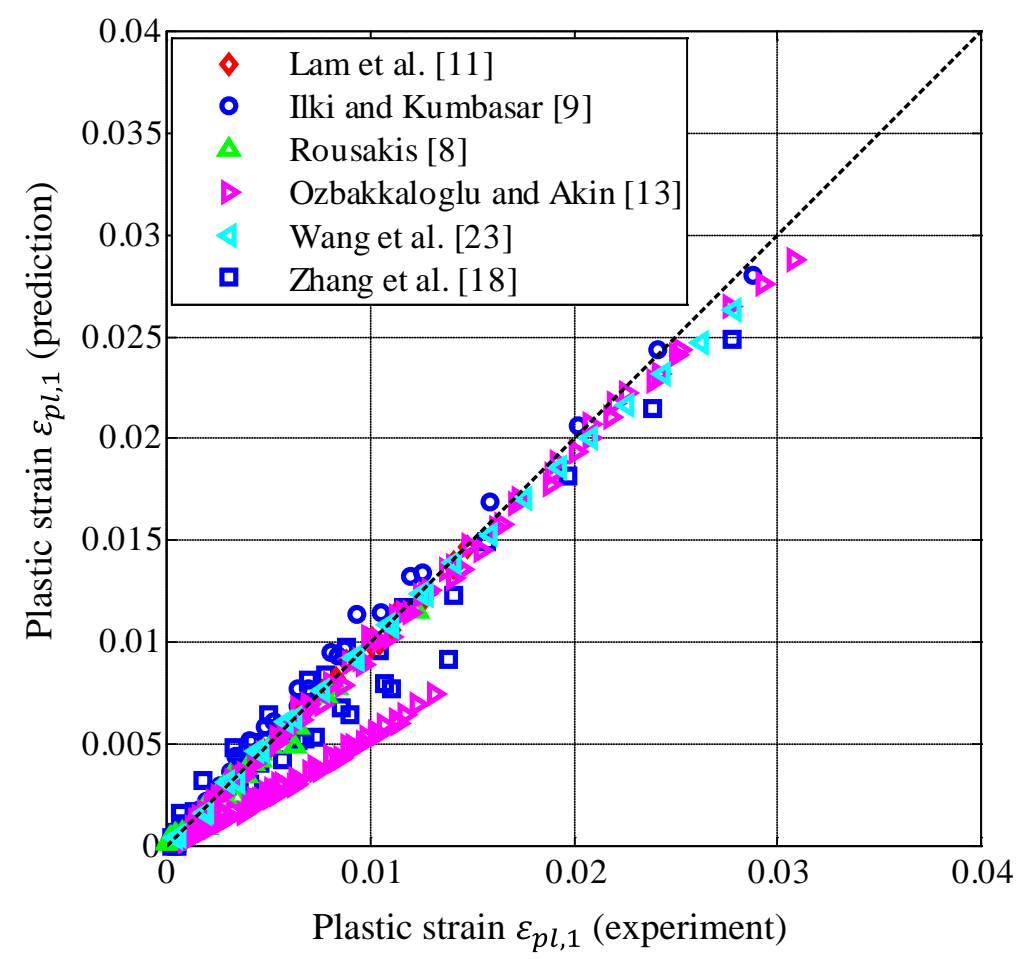

(a) Eq. 18 (Lam and Teng's [17] equation for $\varepsilon_{p l, 1}$ )

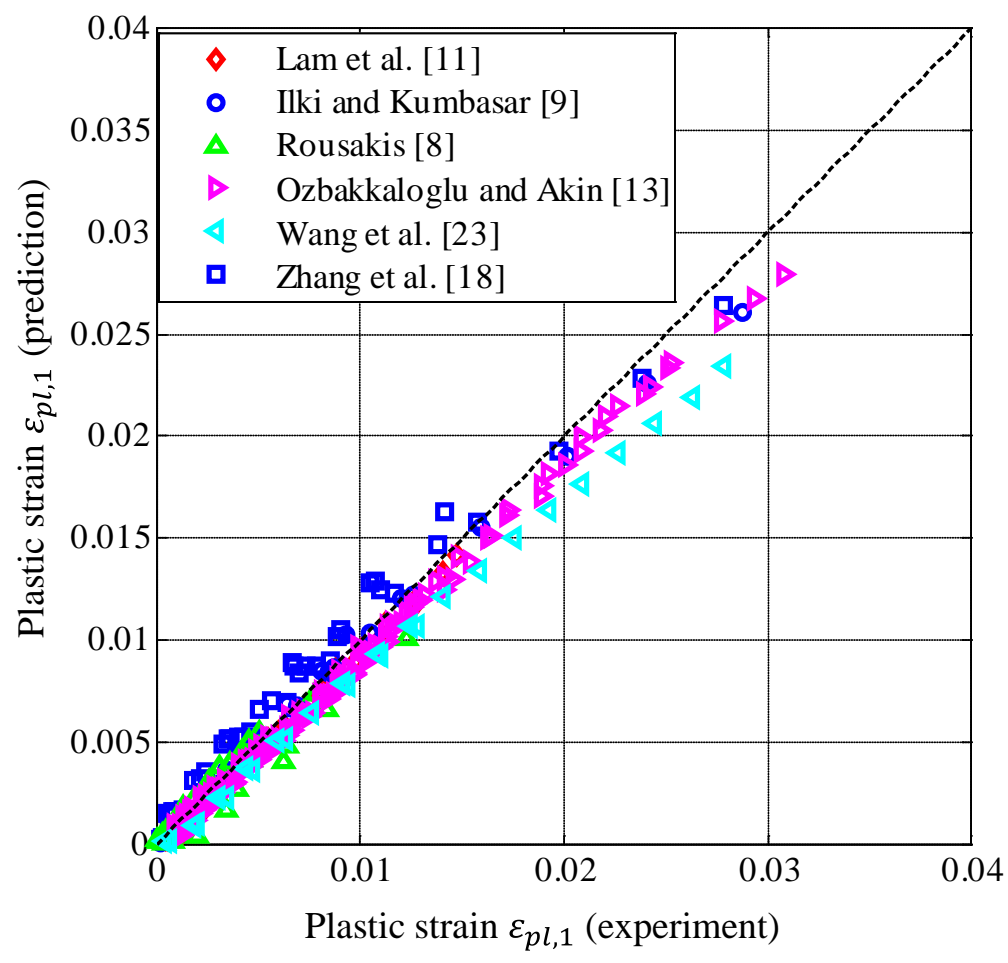

(b) Eq. 19 (Proposed equation for $\varepsilon_{p l, 1}$ )

Figure 6: Performance of equations for the plastic strain of envelope cycles 


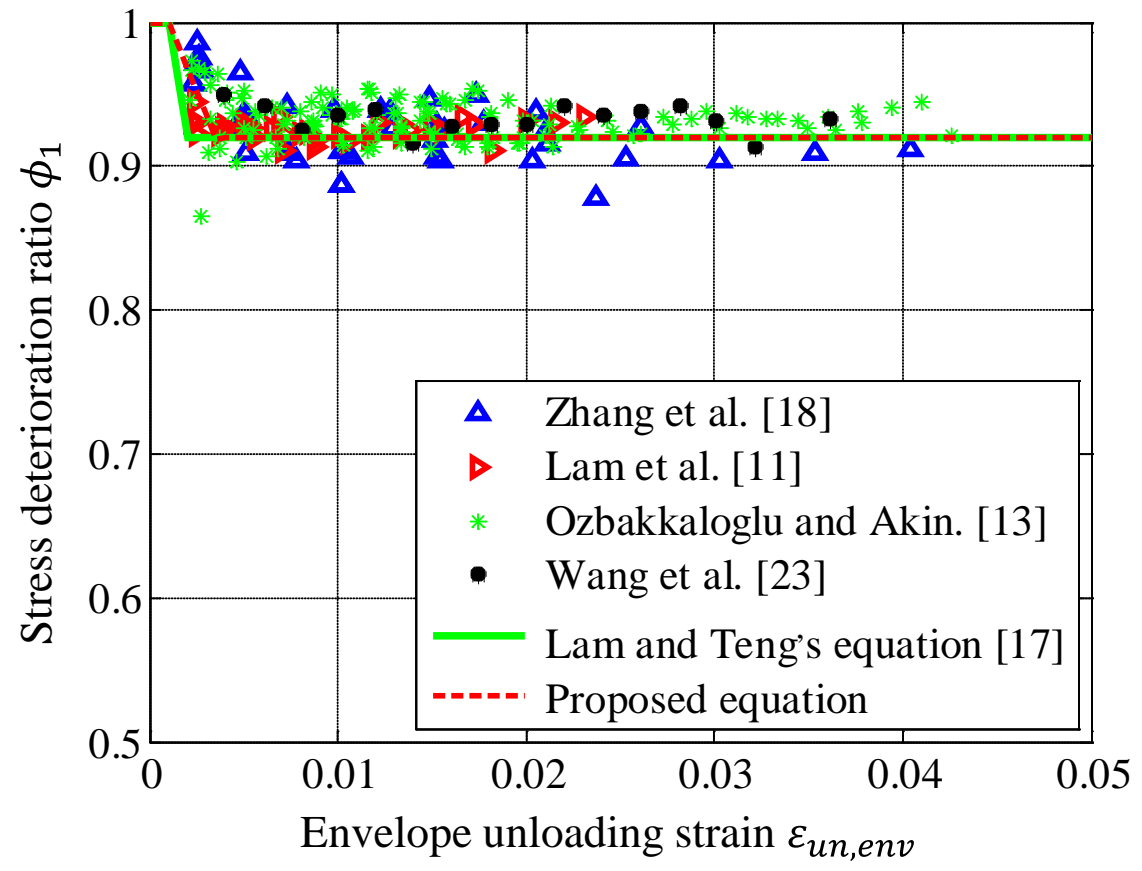

Figure 7: Performance of equations for the stress deterioration ratio of envelope cycles 


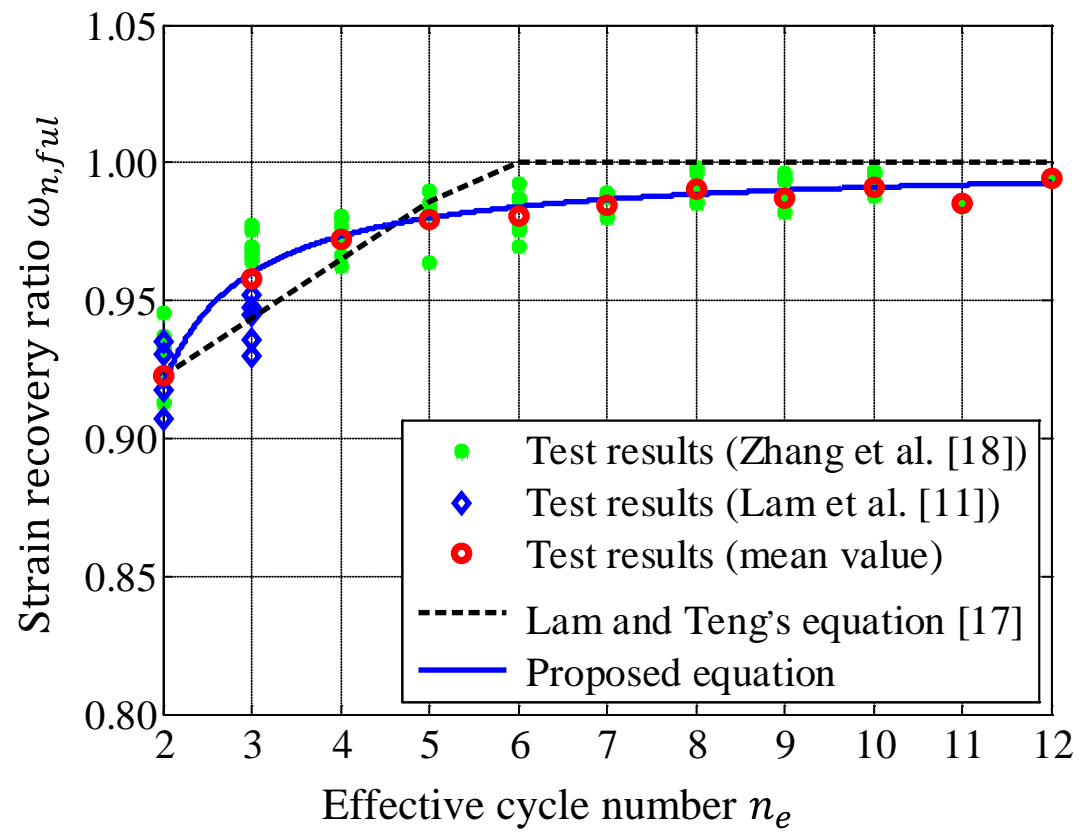

Figure 8: Performance of equations for the strain recovery ratio of internal cycles

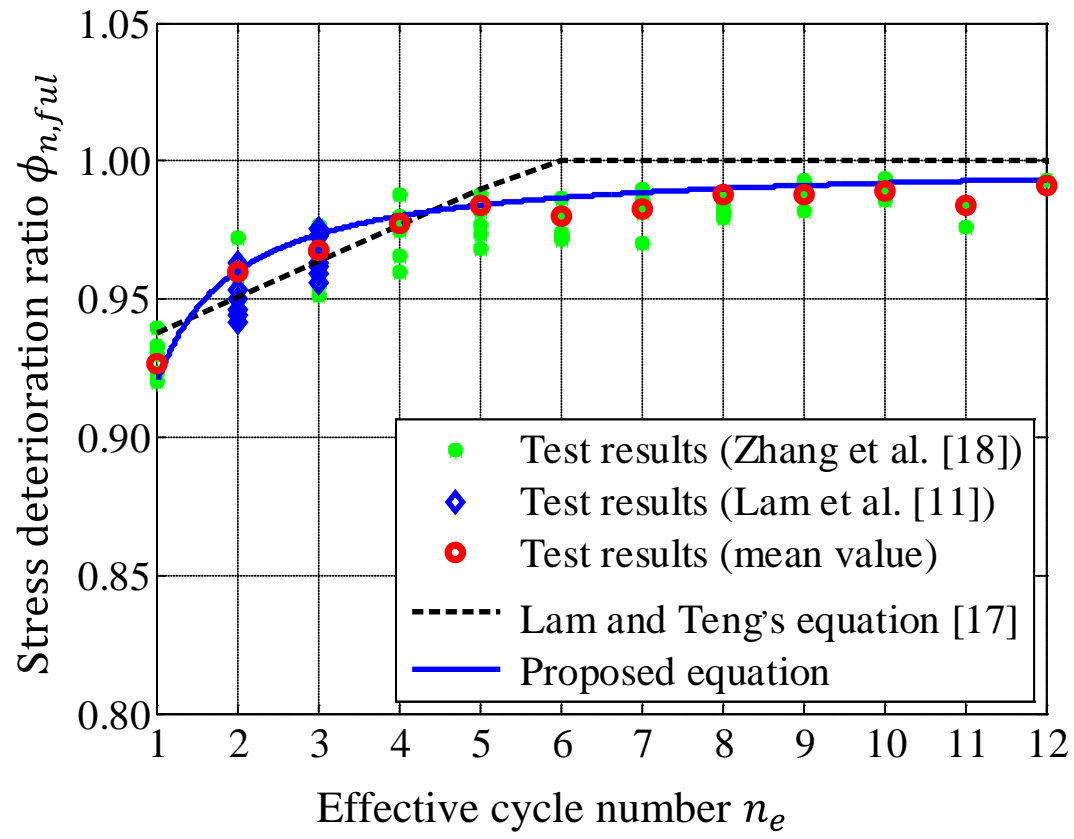

Figure 9: Performance of equations for the stress deterioration ratio of internal cycles 

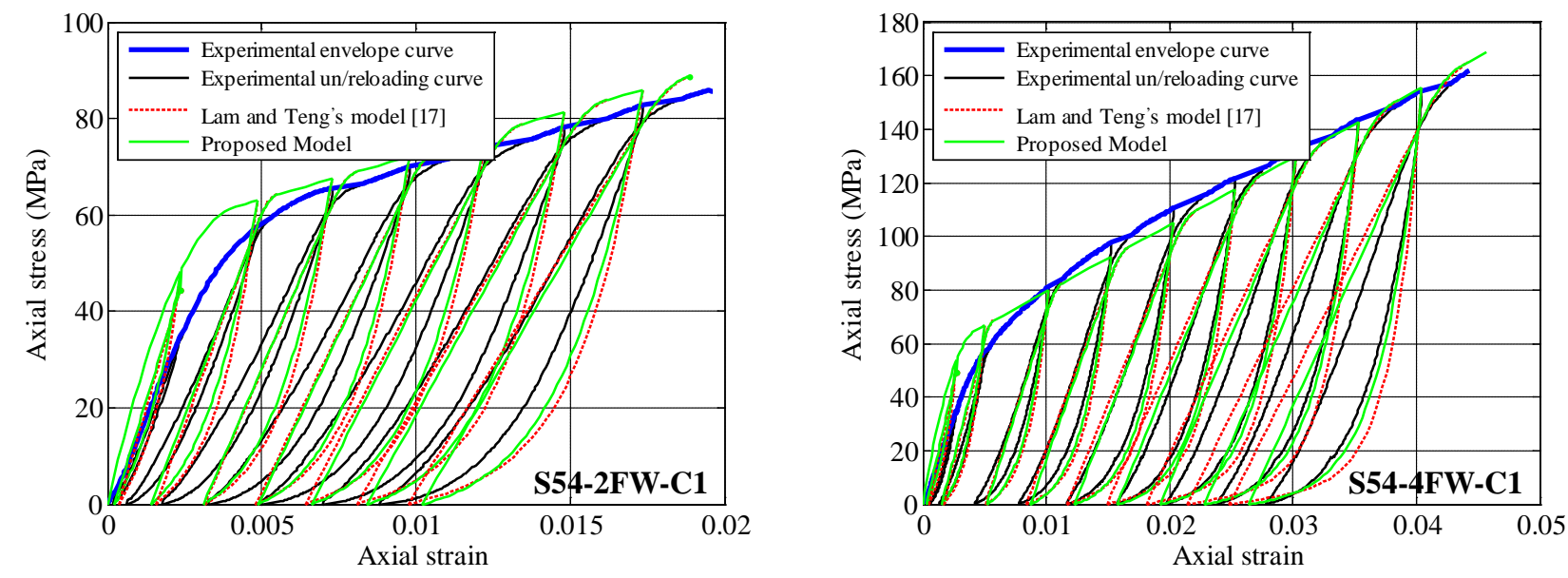

(a) Specimens of Batch 1, $f_{c o}^{\prime}=54.1 \mathrm{MPa}$
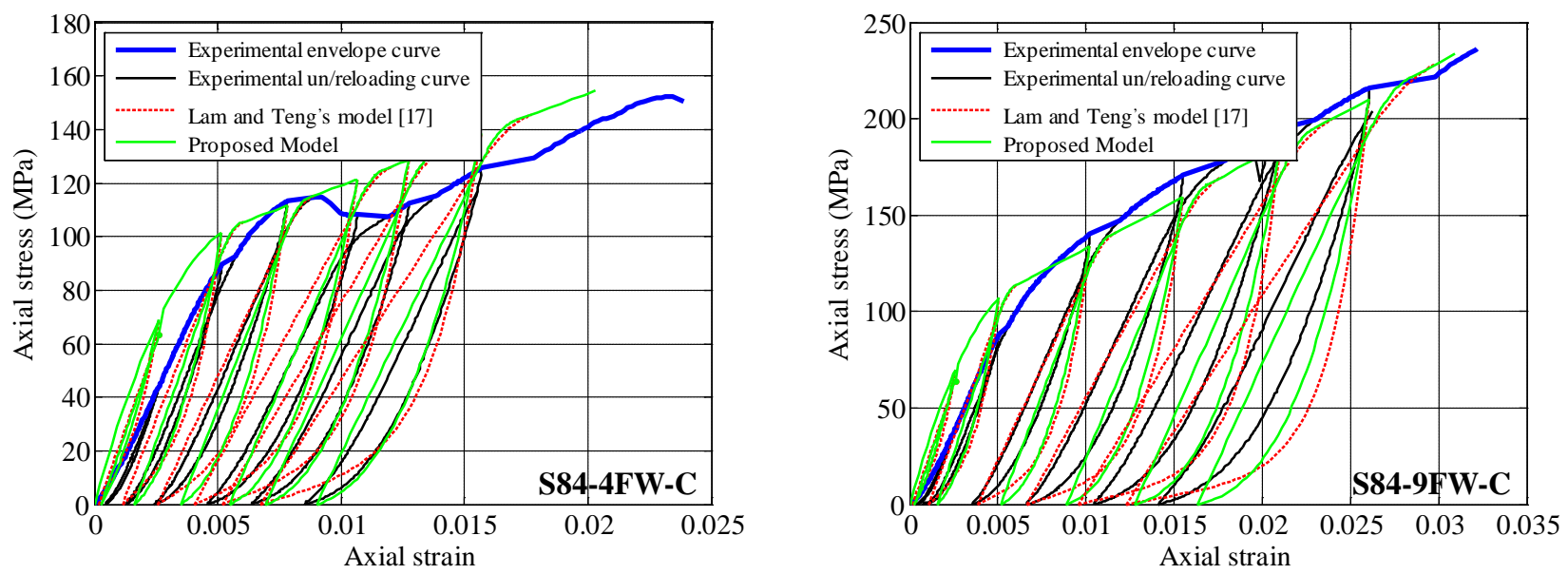

(b) Specimens of Batch 2, $f_{c o}^{\prime}=84.6 \mathrm{MPa}$
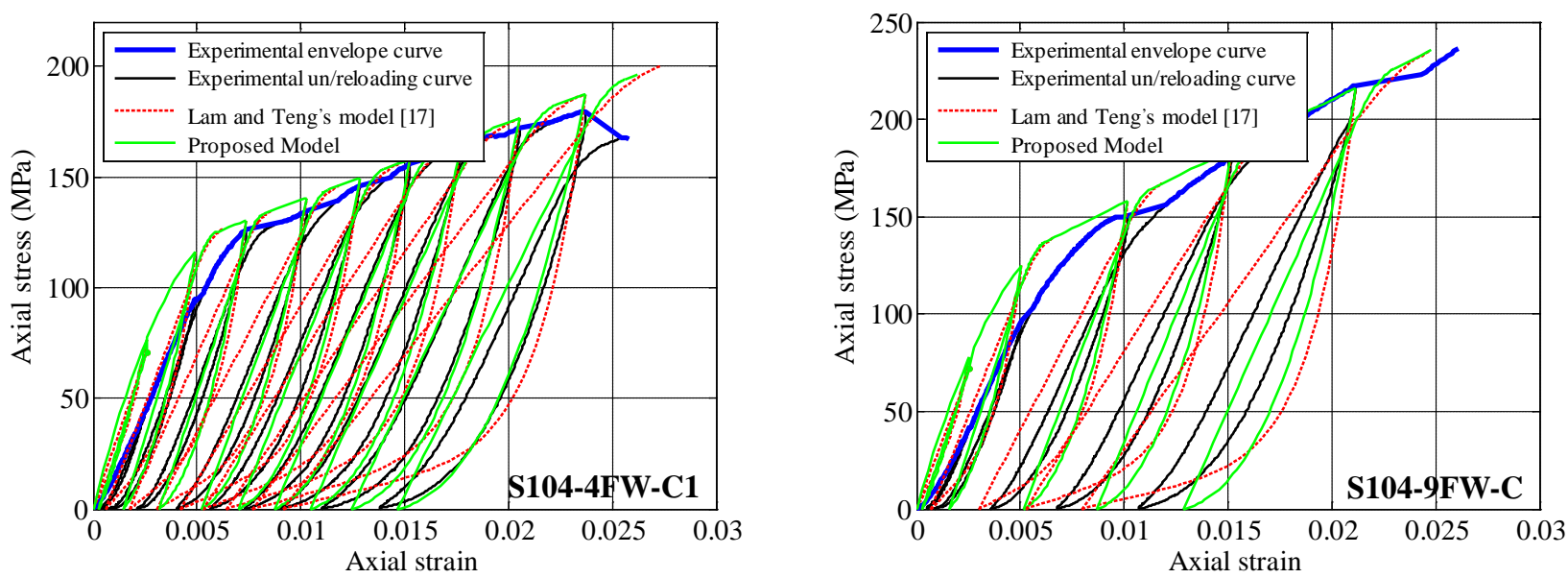

(c) Specimens of Batch 3, $f_{c o}^{\prime}=104.4 \mathrm{MPa}$

Figure 10: Performance of the two stress-strain models for envelope unloading/reloading curves: predictions based on the predicted values of $\varepsilon_{p l, 1}$ 

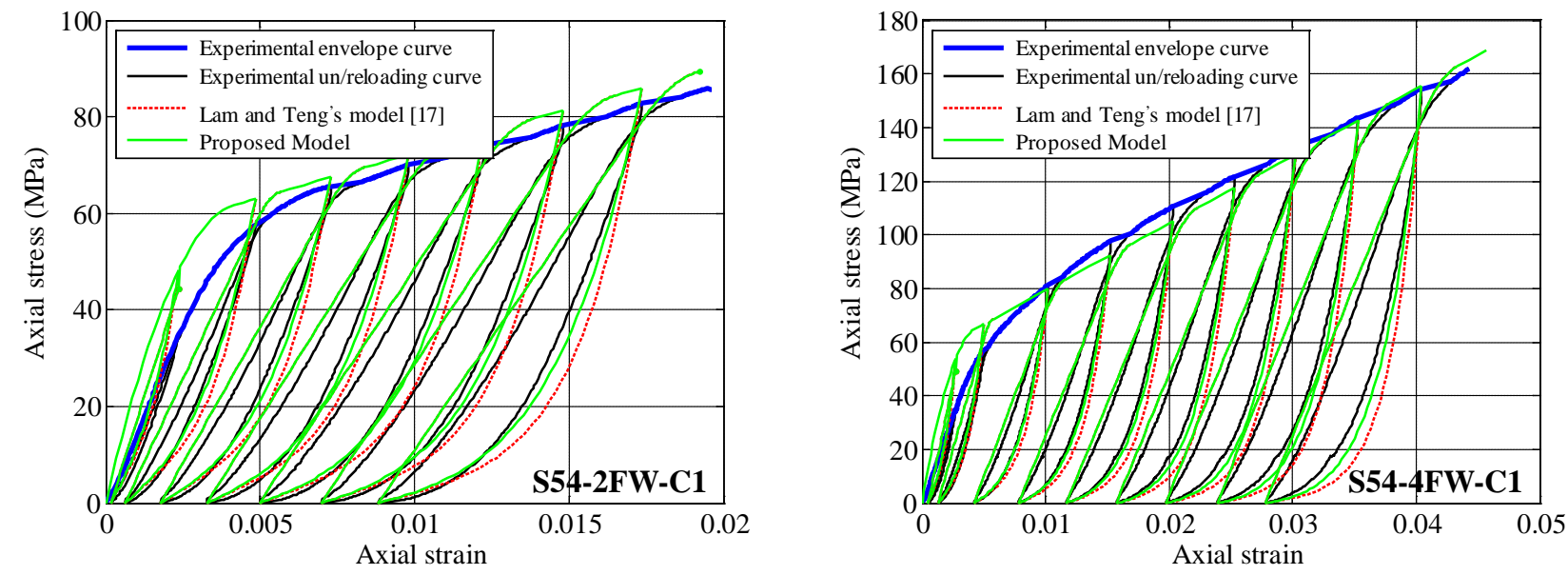

(a) Specimens of Batch 1, $f_{c o}^{\prime}=54.1 \mathrm{MPa}$
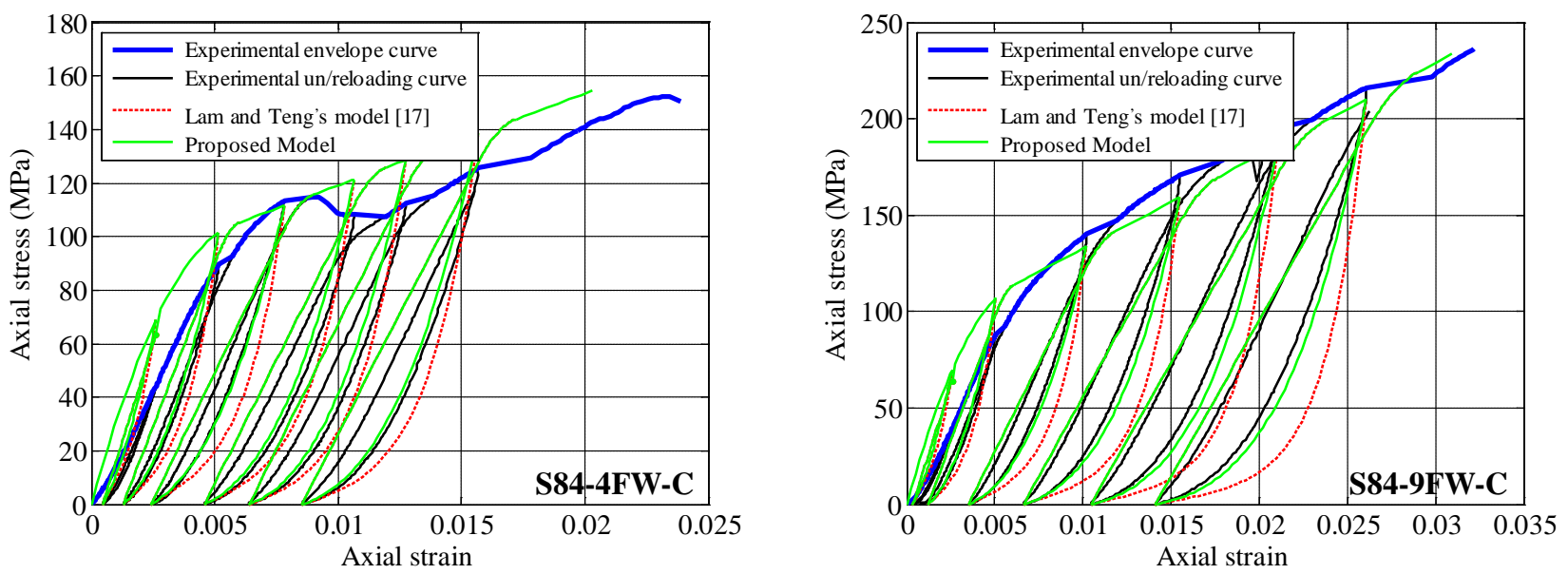

(b) Specimens of Batch 2, $f_{c o}^{\prime}=84.6 \mathrm{MPa}$
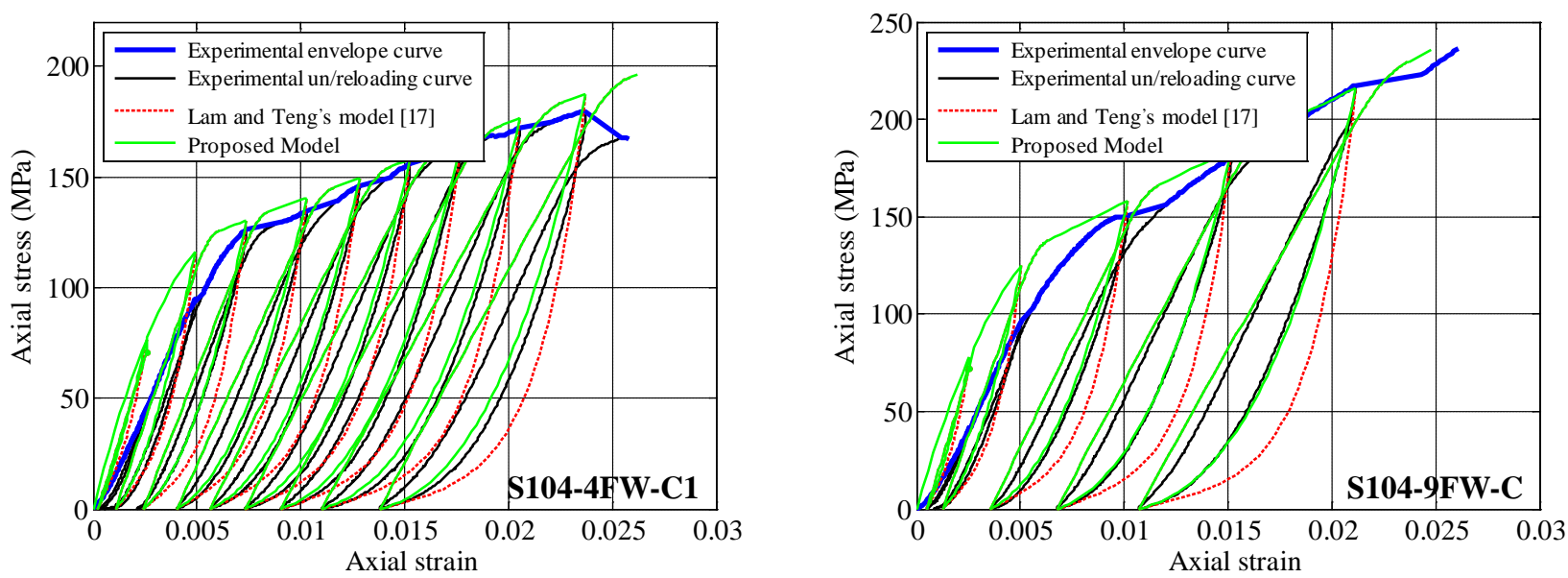

(c) Specimens of Batch 3, $f_{c o}^{\prime}=104.4 \mathrm{MPa}$

Figure 11: Performance of the two stress-strain models for envelope unloading/reloading curves: predictions based on experimental values of $\varepsilon_{p l, 1}$ 

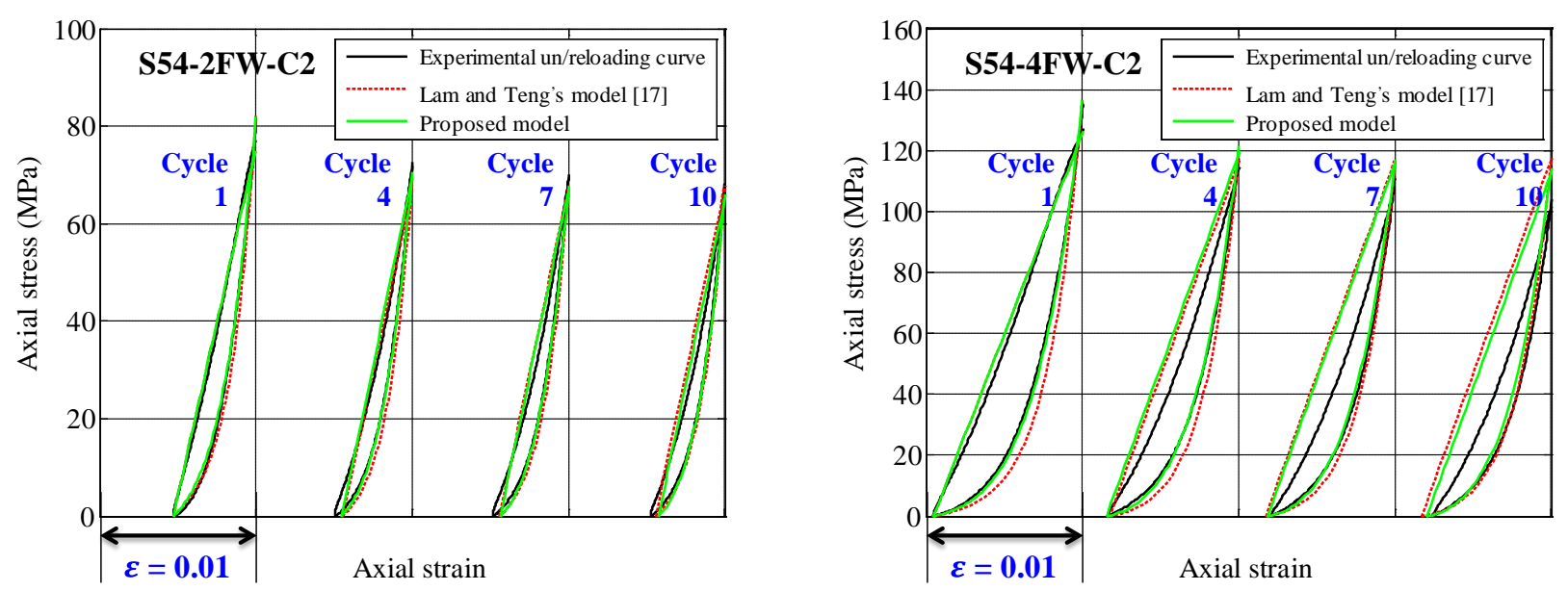

(a) Specimens of Batch 1, $f_{c o}^{\prime}=54.1 \mathrm{MPa}$
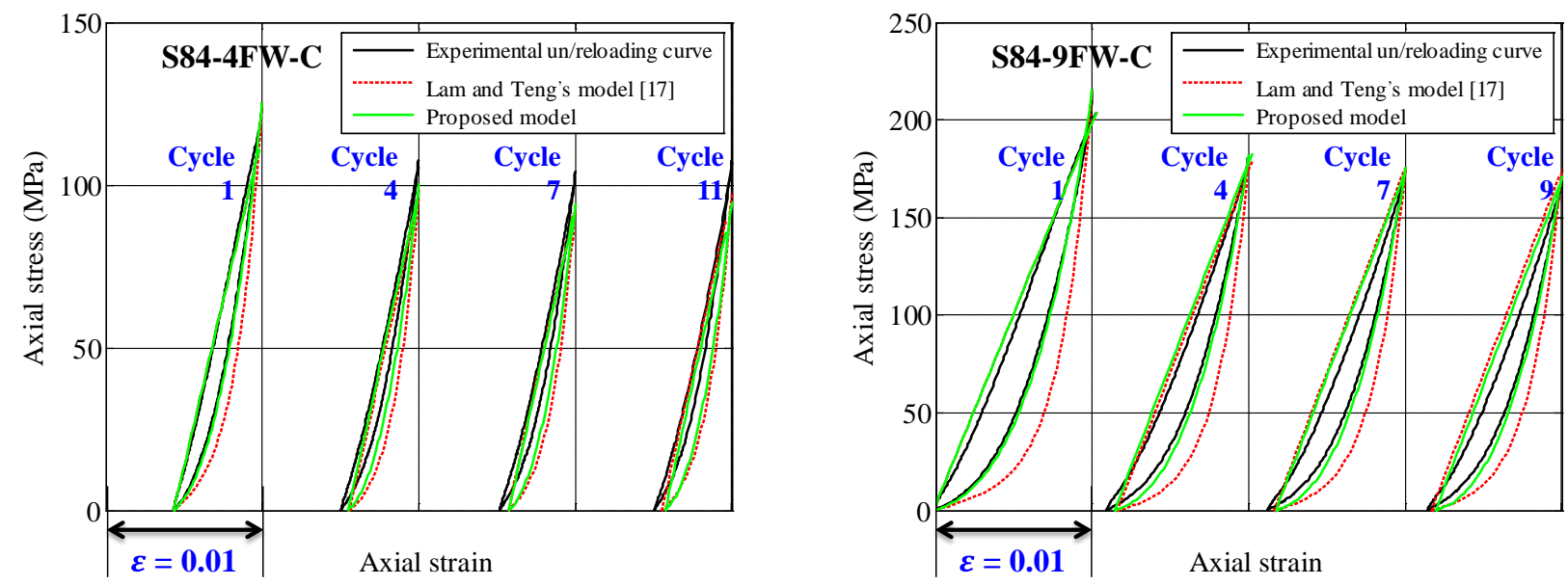

(b) Specimens of Batch 2, $f_{c o}^{\prime}=84.6 \mathrm{MPa}$
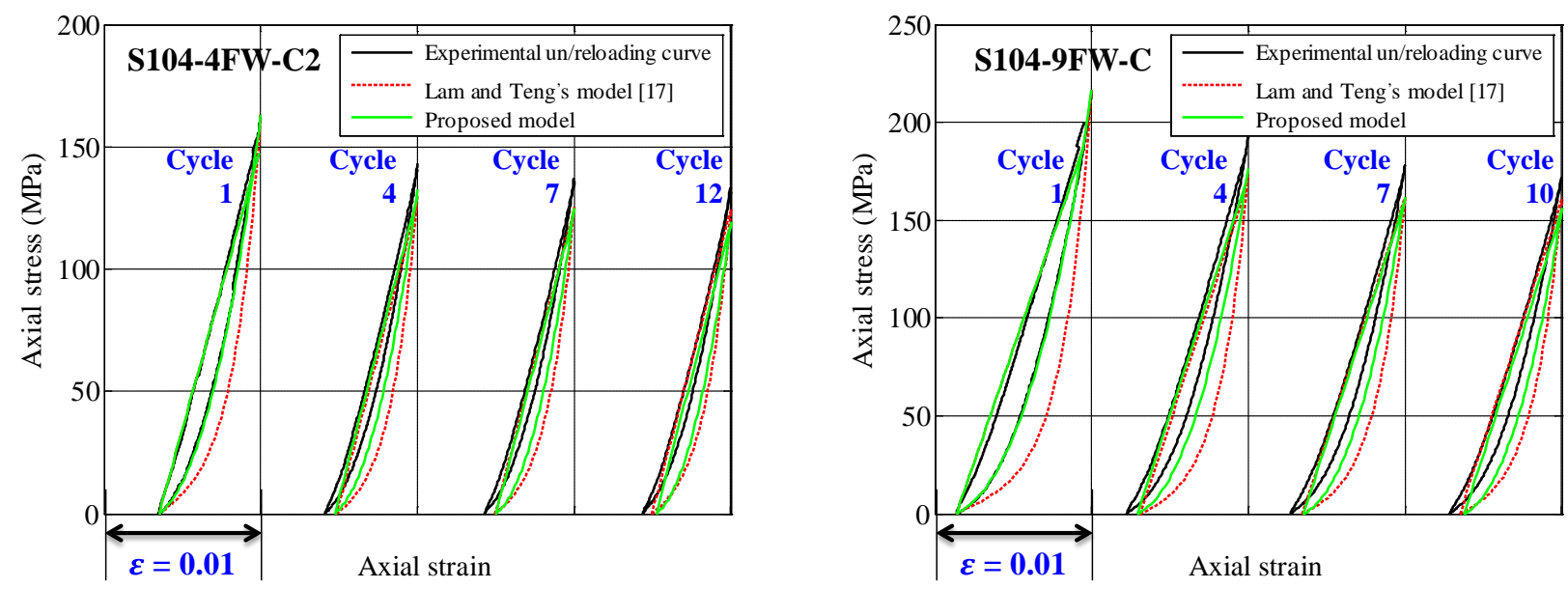

(c) Specimens of Batch 3, $f_{c o}^{\prime}=104.4 \mathrm{MPa}$

Figure 12: Performance of the two stress-strain models for repeated internal unloading/reloading curves; predictions based on the experimental values of $\varepsilon_{p l, 1}$ 
Table 1: Key information of cyclic compression tests in the database

\begin{tabular}{|c|c|c|c|c|c|c|}
\hline Specimen Name & $\begin{array}{l}\text { Unconfined } \\
\text { concrete } \\
\text { strength } \\
f_{c o}^{\prime}(\mathrm{MPa})\end{array}$ & $\begin{array}{c}\text { Thickness of } \\
\text { FRP } \\
t \text { (mm) }\end{array}$ & $\begin{array}{c}\text { Elastic modulus of } \\
\text { FRP } \\
E_{f r p}(\mathrm{GPa})\end{array}$ & $\begin{array}{c}\text { FRP hoop } \\
\text { rupture strain } \\
\varepsilon_{h, \text { rup }}\end{array}$ & $\begin{array}{l}\text { Ultimate } \\
\text { axial } \\
\text { strain } \varepsilon_{c u}\end{array}$ & $\begin{array}{c}\text { Confined } \\
\text { concrete } \\
\text { strength } f_{c c}^{\prime} \\
(\mathrm{MPa})\end{array}$ \\
\hline \multicolumn{7}{|c|}{ Rousakis [8]: 150mm in diameter; 300 mm in height; wet-layup FRP wraps } \\
\hline 20c1L1C & 26.5 & 0.17 & \multirow{15}{*}{$\begin{array}{l}\text { CFRP: } 377 \text { GPa in } \\
\text { hoop direction }\end{array}$} & 0.00639 & 0.0153 & 44.1 \\
\hline 20c1L2C & 26.5 & 0.34 & & 0.00569 & 0.0208 & 61.6 \\
\hline 20c1L3C & 26.5 & 0.51 & & 0.00435 & 0.0244 & 70.2 \\
\hline 40c1L2C & 49.5 & 0.34 & & 0.00540 & 0.0133 & 79.2 \\
\hline 40c1L3C & 49.5 & 0.51 & & 0.00615 & 0.0181 & 104.0 \\
\hline 60ac1L1C & 65.5 & 0.17 & & 0.00517 & 0.0068 & 79.2 \\
\hline 60ac1L2C & 65.5 & 0.34 & & 0.00513 & 0.0102 & 90.3 \\
\hline 60ac1L3C & 65.5 & 0.51 & & 0.00559 & 0.0153 & 117.2 \\
\hline 60ac1L5C & 65.5 & 0.85 & & 0.00526 & 0.0181 & 137.9 \\
\hline 80c1L1C & 68.5 & 0.17 & & 0.00663 & 0.0076 & 83.2 \\
\hline 80c1L2C & 68.5 & 0.34 & & 0.00598 & 0.0098 & 107.2 \\
\hline 80c1L3C & 68.5 & 0.51 & & 0.00391 & 0.0110 & 108.2 \\
\hline 100c1L1C & 95.0 & 0.17 & & 0.00333 & 0.0056 & 97.6 \\
\hline 100c1L2C & 95.0 & 0.34 & & 0.00154 & 0.0053 & 98.2 \\
\hline 100c1L3C & 95.0 & 0.51 & & 0.00443 & 0.0098 & 129.6 \\
\hline \multicolumn{7}{|c|}{ Ilki and Kumbasar [9]: 150mm in diameter; 300 mm in height; wet-layup FRP wraps } \\
\hline $3-14-S$ & 32.0 & 0.165 & \multirow{3}{*}{$\begin{array}{l}\text { CFRP: } 230 \text { GPa in } \\
\text { hoop direction }\end{array}$} & 0.0079 & 0.0144 & 47.2 \\
\hline $3-15-S$ & 32.0 & 0.495 & & 0.0108 & 0.0392 & 91.0 \\
\hline $3-18-S$ & 32.0 & 0.825 & & 0.0100 & 0.0432 & 107.7 \\
\hline \multicolumn{7}{|c|}{ Lam et al. [11] : 152mm in diameter; 305 mm in height; wet-layup FRP wraps } \\
\hline CI-SC1 & 41.1 & 0.165 & \multirow{3}{*}{$\begin{array}{l}\text { CFRP: } 250 \mathrm{GPa} \text { in } \\
\text { hoop direction }\end{array}$} & 0.0132 & 0.0134 & 60.2 \\
\hline CI-SC2 & 41.1 & 0.165 & & 0.0103 & 0.0117 & 56.8 \\
\hline CI-RC $^{\mathrm{a}}$ & 41.1 & 0.165 & & 0.0113 & 0.0120 & 56.5 \\
\hline CII-SC1 & 38.9 & 0.33 & \multirow{3}{*}{$\begin{array}{c}\text { CFRP: } 247 \text { GPa in } \\
\text { hoop direction }\end{array}$} & 0.0122 & 0.0244 & 81.5 \\
\hline CII-SC2 & 38.9 & 0.33 & & 0.0108 & 0.0189 & 78.2 \\
\hline CII-RC $^{\mathrm{a}}$ & 38.9 & 0.33 & & 0.0122 & 0.0234 & 85.6 \\
\hline \multicolumn{7}{|c|}{ Ozbakkaloglu and Akin [13]: 152mm in diameter; 305 mm in height; wet-layup FRP wraps } \\
\hline N-A-2L-C1 & 38.0 & 0.400 & \multirow{8}{*}{$\begin{array}{l}\text { AFRP: } 120 \text { GPa in } \\
\text { hoop direction }\end{array}$} & 0.0150 & 0.0225 & 64.3 \\
\hline $\mathrm{N}-\mathrm{A}-2 \mathrm{~L}-\mathrm{C} 2$ & 39.0 & 0.400 & & 0.0156 & 0.0225 & 64.3 \\
\hline N-A-3L-C1 & 39.0 & 0.600 & & 0.0176 & 0.0404 & 97.4 \\
\hline N-A-3L-C2 & 39.0 & 0.600 & & 0.0202 & 0.0443 & 104.5 \\
\hline H-A-4L-C1 & 100.0 & 0.800 & & 0.0124 & 0.0182 & 136.4 \\
\hline H-A-4L-C2 & 102.0 & 0.800 & & 0.0110 & 0.0163 & 125.4 \\
\hline H-A-6L-C1 & 104.0 & 1.20 & & 0.0116 & 0.0187 & 157.2 \\
\hline H-A-6L-C2 & 106.0 & 1.20 & & 0.0145 & 0.0213 & 170.9 \\
\hline H-C-4L-C1 & 100.0 & 0.468 & \multirow{4}{*}{$\begin{array}{l}\text { CFRP: } 240 \mathrm{GPa} \text { in } \\
\text { hoop direction }\end{array}$} & 0.0069 & 0.0107 & 102.3 \\
\hline H-C-4L-C2 & 100.0 & 0.468 & & 0.0081 & 0.0106 & 96.0 \\
\hline H-C-6L-C1 & 109.0 & 0.702 & & 0.0064 & 0.0114 & 123.7 \\
\hline H-C-6L-C2 & 105.0 & 0.702 & & 0.0081 & 0.0116 & 129.9 \\
\hline
\end{tabular}




\begin{tabular}{|c|c|c|c|c|c|c|}
\hline \multicolumn{7}{|c|}{ Wang et al. [23]: 204mm in diameter; $612 \mathrm{~mm}$ in height; wet-layup FRP wraps } \\
\hline C2H0L1C & 24.5 & 0.167 & CFRP: 244 GPa in & 0.0145 & 0.0194 & 42.3 \\
\hline C2H0L2C & 24.5 & 0.334 & hoop direction & 0.0136 & 0.0382 & 66.8 \\
\hline \multicolumn{7}{|c|}{ Zhang et al. [18]: 200mm in diameter; $400 \mathrm{~mm}$ in height; filament-wound FRP tubes } \\
\hline S54-2FW-C1 & 54.1 & 2.2 & & 0.0108 & 0.0176 & 86.0 \\
\hline S54-2FW-C2 ${ }^{\mathrm{b}}$ & 54.1 & 2.2 & & 0.0111 & 0.0189 & 88.7 \\
\hline S54-4FW-C1 & 54.1 & 4.7 & & 0.0168 & 0.0442 & 161.7 \\
\hline S54-4FW-C2 ${ }^{\mathrm{b}}$ & 54.1 & 4.7 & GFRP: in hoop & 0.0169 & 0.0443 & 159.4 \\
\hline S84-4FW-C ${ }^{b}$ & 84.6 & 4.7 & direction $45.9 \mathrm{GPa}$; & 0.0110 & 0.0239 & 152.3 \\
\hline S84-9FW-C ${ }^{b}$ & 84.6 & 9.5 & & 0.0105 & 0.0322 & 236.2 \\
\hline S104-4FW-C1 & 84.6 & 4.7 & & 0.0132 & 0.0258 & 179.6 \\
\hline S104-4FW-C2 ${ }^{b}$ & 104.4 & 4.7 & & 0.0109 & 0.0238 & 167.6 \\
\hline S104-9FW-C ${ }^{b}$ & 104.4 & 9.5 & & 0.0093 & 0.0261 & 236.4 \\
\hline
\end{tabular}

${ }^{a}$ Specimens tested by Lam et al. [11] which were subjected to 3 unloading/reloading cycles at each prescribed unloading displacement level;

b Specimens tested by Zhang et al. [18] which were subjected to 9 12 unloading/reloading cycles at a prescribed unloading displacement level.

Table 2: Linear relationships between unloading strains and plastic strains

\begin{tabular}{|c|c|c|c|c|}
\hline \multirow{2}{*}{ Source of test data } & \multirow{2}{*}{$\begin{array}{l}\text { Unconfined concrete } \\
\text { strength } f_{c o}^{\prime}(\mathrm{MPa})\end{array}$} & \multicolumn{2}{|c|}{$\varepsilon_{p l, 1}=a \varepsilon_{u n, e n v}+b$} & \multirow{2}{*}{$\mathrm{R}^{2}$} \\
\hline & & $\mathrm{a}$ & $\mathrm{b}$ & \\
\hline \multirow{5}{*}{ Rousakis [8] } & 26.5 & 0.744 & -0.0006 & 0.987 \\
\hline & 49.5 & 0.737 & -0.0020 & 0.981 \\
\hline & 65.5 & 0.601 & -0.0015 & 0.981 \\
\hline & 68.5 & 0.603 & -0.0015 & 0.968 \\
\hline & 95.0 & 0.467 & -0.0013 & 0.999 \\
\hline Ilki and Kumbasar [9] & 32.0 & 0.713 & -0.0019 & 0.994 \\
\hline \multirow{2}{*}{ Lam et al. [11] } & 38.9 & 0.714 & -0.0016 & 0.998 \\
\hline & 41.1 & 0.703 & -0.0014 & 0.996 \\
\hline \multirow{6}{*}{ Ozbakkaloglu and Akin [13] } & $38.0 \sim 39.0$ & 0.736 & -0.0016 & 0.999 \\
\hline & 39.0 & 0.743 & -0.0017 & 0.999 \\
\hline & $100.0 \sim 102.0$ & 0.805 & -0.0021 & 0.996 \\
\hline & 104.0 106.0 & 0.775 & -0.0022 & 0.998 \\
\hline & 100.0 & 0.760 & -0.0020 & 0.995 \\
\hline & 105.0 109.0 & 0.760 & -0.0023 & 0.999 \\
\hline Wang et al. [23] & 24.5 & 0.815 & -0.002 & 0.999 \\
\hline \multirow{6}{*}{ Zhang et al. [18] } & 54.1 & 0.665 & -0.0030 & 0.993 \\
\hline & 54.1 & 0.764 & -0.0034 & 0.998 \\
\hline & 84.6 & 0.708 & -0.0027 & 0.989 \\
\hline & 84.6 & 0.638 & -0.0028 & 0.996 \\
\hline & 104.4 & 0.695 & -0.0031 & 0.997 \\
\hline & 104.4 & 0.614 & -0.0024 & 0.998 \\
\hline
\end{tabular}

